\title{
3D numerical modeling of flow characteristics in an open channel having in-line circular vegetation patches with varying density under submerged and emergent flow conditions
}

\author{
Hasnain Tariq ${ }^{1}$, Usman Ghani ${ }^{1 *}$, Naveed Anjum ${ }^{2}$, Ghufran Ahmed Pasha ${ }^{1}$ \\ ${ }^{1}$ Department of Civil Engineering, University of Engineering and Technology, 47050, Taxila, Pakistan. \\ ${ }^{2}$ Graduate School of Science and Engineering, Saitama University, Saitama, Japan, 255 Shimookubo, Sakura Ward, Saitama, 338-8570, Japan. \\ * Corresponding author. Tel.: +92 51-9047647. E-mail: usman.ghani@uettaxila.edu.pk
}

\begin{abstract}
In the marine ecological system, the prime role of water management and durability of an ecosystem is being played by the vegetation patches. The vegetation patches in open channels can significantly affect the flow velocity, discharge capacity and hinder energy fluxes, which ultimately helps in controlling catastrophic floods. In this study, the numerical simulation for turbulent flow properties, i.e. velocity distribution, Reynolds stresses and Turbulent Intensities (TI) near the circular vegetation patches with progressively increasing density, were performed using the computational fluid dynamics (CFD) code ANSYS FLUENT. For examination of the turbulent flow features in the presence of circular patches with variable densities, Reynolds averaged Navier-Stokes equations, and Reynolds stress model (RSM) were employed. The numerical investigation was performed in the presence of in-line emergent and submerged patches having variable vegetation density in the downstream direction. Two of the cases were investigated with three circular patches having a clear gap to patch diameter ratio of $L_{a} / D=1$ (where $L_{a}$ is the clear spacing between the vegetation patches and $D$ is the diameter of the circular patch), and the other two cases were analyzed with two patches having a clear gap ratio of $L_{a} / D=3$. The case with a clear gap ratio $\left(L_{a} / D=3\right)$ showed $10.6 \%$ and $153 \%$ inflation in the magnitude of longitudinal velocity at the downstream of the sparse patch $(a D=0.8)$ and upstream of the dense patch $(a D=3.54)$, respectively (where $a D$ is the flow blockage, in which " $a$ " represents the patch frontal area and " $D$ " represents the patch diameter). The velocity was reduced to $94 \%$ for emergent and $99 \%$ for submerged vegetation due to successive increase in vegetation density made by introducing a middle patch which reduced the clear gap ratio $\left(L_{a} / D=1\right)$. For $L_{a} / D=1$, the longitudinal velocities at depth $z=15 \mathrm{~cm}$ were increased by $319 \%$ than at depth $z=6 \mathrm{~cm}$ at the downstream of the dense patch $(a D=3.54)$. Whereas it was observed to $365 \%$ higher in the case of $L_{a} / D=3$. The magnitude of turbulent characteristics was observed $36 \%$ higher for submerged vegetation cases having a clear gap ratio of $L_{a} / D=1$. The successive increase in the patch density reduced the Reynolds stresses, turbulent kinetic energy and turbulent intensities significantly within the gap region. The major reduction in the flow velocities and turbulent properties in the gaps provides a stable environment for aquatic ecosystems nourishment and fosters sediment deposition, and supports further vegetation growth.
\end{abstract}

Keywords: Vegetation patches; Open channel; Variable patch density; Flow velocity; Turbulence.

\section{INTRODUCTION}

In the field of hydraulics, the impact of vegetation on the flow has vibrant significance (Nepf, 1999). Vegetation has a vital part in developing the aquatic biological environment (Yu et al., 2013). Vegetation plays an essential role in the floodplain or channel during high-speed flows (Neary et al., 2012). Vegetation is a regular and irregular combination of trees, herbs, grasses, and mangroves (that usually grow in wetlands), floodplains, and waterway beds that control pollutant and sediment conveyance (Zhang et al., 2013). Vegetation causes flow obstruction, which increases the depth of flow and ends up with a reduction in velocity and shear stresses. This phenomenon is applicable for energy dissipation and riverbanks stabilization (Pasha et al., 2018). It is a well-known fact that the channel morphology of unmaintained river channels is recovered through riparian vegetation (Bertoldi et al., 2014; Prasad and Tang, 2015). The reduced velocity and shear stress in the channel provoke sediment to settle on the bed of the channel (Jordanova and James, 2003). Several investigators have deliberated the outcomes using experimental setup and numerical models to observe the spatial patterns of turbulence, sedimentation and erosion and other flow features in the presence of vegetation (Maltese et al., 2007). Hao et al. (2014) examined the bed shear stress in the presence of emergent vegetation due to variation in size of sediment, the slope of channel and vegetation stem density. Kouwen and Unny (1973) performed a number of studies on additional resistance produced by vegetation cover and the change of flow conditions in the channel. Many earlier experimental studies have been performed in the laboratory flumes to understand the behavior of streamwise velocities and turbulence of flow downstream of the vegetation patch. For example, Neumeier (2007) concluded in his experiment that vegetation causes an increase in the irregularity of flow on the sides of the patch and decreases turbulence in the dense patch, which leads to sediment settlement. Dan et al. (1996) observed the effect of vegetation cover density, patch diameter over the flow through the rectangular waterway and examined the hydrodynamic effect of flow on the streambed, corner and riparian vegetation. Cheng (2011) worked on the underwater vegetation and calculated the effect of immersed vegetation. Both patch diameter and patch density are directly linked with the roughness height. 
In numerical modeling, two methods are commonly adopted for simulation. Firstly, a body model which studies every individual vegetation element (Zhang et al., 2015). Secondly, a porous model that considers the overall vegetation patch (Xiaohui and Li, 2002). Yu et al. (2013) calculated the drag coefficient using multi-body model (vegetation element) and implemented it into a porous model (vegetation zone). Kamel et al. (2014) utilized the non-linear 3D model to observe flow structure and velocity distribution in an open channel with various curves. Zhenqun et al. (2020) worked on the special properties of water, which influence the flow structure under the variation of particle properties. Jalonen et al. (2015) developed the methodology to estimate the behavior of flow characteristics by implementing the practical data gathered from the floodplain area and experimental setup in the laboratory. Devi and Kumar (2016) examined the properties of flow under immersed vegetation condition with different spacing. López and García (1998) investigated the mean stream discharge and turbulence pattern of the free surface channel using the k-epsilon model (two-equation model). Zhao and Huai (2016) used Large Eddy Simulation (LES) model to check the turbulence of flow and mean velocity due to interaction of the discontinuous rigid vegetation patch. Xiaonan and Knight (2009) performed analysis using Reynolds Average Navier Stokes (RANS) equation on floodplain covered with partial vegetation and examined the resultant flow structure. Huai et al. (2014) analyzed the flow characteristics using double-layered vegetation covers. Anjum et al. (2018a) used the 3D Reynold stress model (RSM) to examine the distribution of Reynold stresses and depthwise velocities in the existence of double height vegetation cover.

Suk et al. (2015) performed numerical simulation using emerged rigid vegetation by carrying out the LES method. Zeng and $\mathrm{Li}$ (2014) constructed a 3D numerical model to examine the flow features through semi-flexible vegetation by applying the LES model. Anjum et al. (2018b) and Takemura and Tanaka (2007) explored the influence on the flow features by introducing a circular patch in the channel keeping the staggered arrangement of cylinders. Dieter et al. (2014) experimented on two emergent circular vegetation patches adjacent to each other. They extracted the flow features and deposition by changing the gaps between the patches. Ghisalberti and Nepf (2004) and Bouma et al. (2007) found great consistency among experimental and numerical setup for velocity profiles of shear layer caused by vegetation using the k- $\varepsilon$ model. Zong and Nepf (2011) delineated the steady wake features generated behind the circular patch due to the intrusion of emergent vegetation patch in the flow. Zhan et al. (2017) calculated the flow features through the circular arrangement of cylindrical elements. The flow properties are dependent on the flow blockage, which is a non-dimensional parameter. The flow blockage is based on the spacing between the vegetation elements and blockage width. For different flow blockage values, Rominger and Nepf (2011) have observed flow behavior due to obstruction as a function of length and array width. The frontal area per unit volume of patch for low flow-blockage defines the adjustment length.

In the past, the influence of the limited length of vegetation (Dan et al., 1996) and single circular patch (Anjum et al., 2018a; Chen et al., 2012; Li et al., 2019; Nishino et al., 2007; Tanaka et al., 1993) on the flow gained much attention. As there are very minute chances of the existence of individual patch on the floodplains and waterways, these patches usually exist in the series or scattered pattern with no uniform stem densities. Therefore, the interaction of neighboring patch is vital for flow evolution, which makes the interaction of flow and vegetation more complicated. There are some studies performed by a few researchers, including
Anjum et al. (2018b), Suk et al. (2015) and Zhan et al. (2017), that adopted the circular vegetation arrangement. The comparisons of the different vegetation density models were analyzed, however, the impact of the successive increase of vegetation density on the flow features in the same model has not been reported yet. In regular flow conditions, vegetation will have a clear height above the water surface, while during flood condition, the vegetation patches will be fully submerged.

As the vegetation cover exists randomly over the floodplain, the interaction of vegetation patches and their influence on the flow features is emerging in the field of hydraulics (Tatsuno et al., 1998). The study of flow behavior in such conditions can yield important results. Therefore, it was found appropriate to explore the influence of the circular vegetation with varying patch density upon flow characteristic and interaction between the vegetation patches using numerical simulation.

This study comprises the detailed analysis of flow behavior in circular patches with a variable streamwise patch density. The detailed examination was carried out by arranging the circular patches with increasing density along the flow direction in a rectangular open channel using Reynold Stress Model (RSM). A numerical model was prepared with three circular patches with gradually increasing density. The model was then simulated and analyzed for emergent and submerged vegetation conditions to examine various three-dimensional flow characteristics such as three-dimensional velocity components, Reynolds stress distributions, and turbulent kinetic energy.

\section{METHODS AND MATERIALS}

\subsection{Experimental data for validation purposes}

The numerical model was validated against the experimental research work performed by Ali et al. (2018). The experiments were conducted in the Hydraulics Laboratory of Civil Engineering Department at the University of Engineering and Technology Taxila, Pakistan. The experiments were performed in a channel having measurements of $1250 \mathrm{~cm}$ in length, $30 \mathrm{~cm}$ in width and $45 \mathrm{~cm}$ in depth. Rigid cylindrical vegetation elements having a diameter $(d)$ of $0.64 \mathrm{~cm}$ and a height of $8 \mathrm{~cm}$ was mounted over the wooden baseboards. The baseboard with dimensions of $100 \mathrm{~cm} \times 30 \mathrm{~cm} \times 1 \mathrm{~cm}$ was placed in the channel to install vegetation elements. The size $(d)$ of cylindrical vegetation elements lay in the range of the emergent vegetation element range, which is $0.1-1 \mathrm{~cm}$ (Leonard and Mark, 1995; Li et al., 2019). The cylinders were straddled over the baseboards in a staggered and circular fashion to get the required arrangement. The stem density was described by $n$, which is the number of vegetation elements per bed area. The frontal area per volume was taken as $a=n d$ (Li et al., 2019; Rominger and Nepf, 2011). The patch diameter $(D)$ for all the patches was taken as $5.76 \mathrm{~cm}$. The spacing between the patches in the longitudinal and transverse direction was $5.76 \mathrm{~cm}$ and $3.18 \mathrm{~cm}$, respectively (as shown in Figure 1(a)). The isometric view of the model is shown in Figure 1(b). In Figure 1(b), the x-axis shows the streamwise flow direction, the $y$-axis shows the lateral direction, and the $\mathrm{z}$-axis shows the vertical direction. The experiments were conducted both for dense and sparse vegetation cases with flow blockage $(a D)$ of 2.3 and 1.2 (Dieter et al., 2014; Ghani et al., 2019a), respectively. All the experiments were performed with a discharge of $9 \mathrm{~L} / \mathrm{s}$. Over here, the sparse vegetation case of the experimental work has been considered for validation purposes.

Different hydraulic conditions for this experimental case are mentioned in Table 1. The data for velocity was measured at every point 15 to 25 times over 20 to 30 seconds. The estimated error was about $1 \%$. 
Table 1. Hydraulic parameters of the experimental work, where $d$ and $D$ represent the diameter of vegetation element and circular patches, respectively, $h$ is the height of vegetation element, flow depth is represented by $z$, discharge is represented by $Q$, frontal area per volume is represented by ' $a$ ', a number of elements per patch area by $n, a D$ is flow blockage, $U_{o}$ is the mean velocity $(U=Q / A), R_{e}$ represents the Reynolds number for flow $\left(R_{e}=U z / v\right), R_{e}^{*}$ is the Reynolds number for cylinder $\left(R_{e}^{*}=U d / v\right)$, and $F_{r}$ is the Froude number.

\begin{tabular}{lcccccccccccc}
\hline Case & $\begin{array}{c}d \\
(\mathrm{~cm})\end{array}$ & $\begin{array}{c}D \\
(\mathrm{~cm})\end{array}$ & $\begin{array}{c}h \\
(\mathrm{~cm})\end{array}$ & $\begin{array}{c}z \\
(\mathrm{~cm})\end{array}$ & $\begin{array}{c}Q \\
(\mathrm{~L} / \mathrm{s})\end{array}$ & $\begin{array}{c}n \\
\left(\mathrm{~cm}^{-2}\right)\end{array}$ & $\begin{array}{c}a=n d \\
\left(\mathrm{~m}^{-1}\right)\end{array}$ & $a D$ & $\begin{array}{c}U_{o} \\
(\mathrm{~m} / \mathrm{s})\end{array}$ & $R_{e}$ & $R_{e}{ }^{*}$ & $F_{r}$ \\
\hline 1 & 0.64 & 5.76 & 8 & 6 & 9 & 0.3 & 21 & 1.2 & 0.501 & 29,920 & 3190 & 0.653 \\
\hline
\end{tabular}

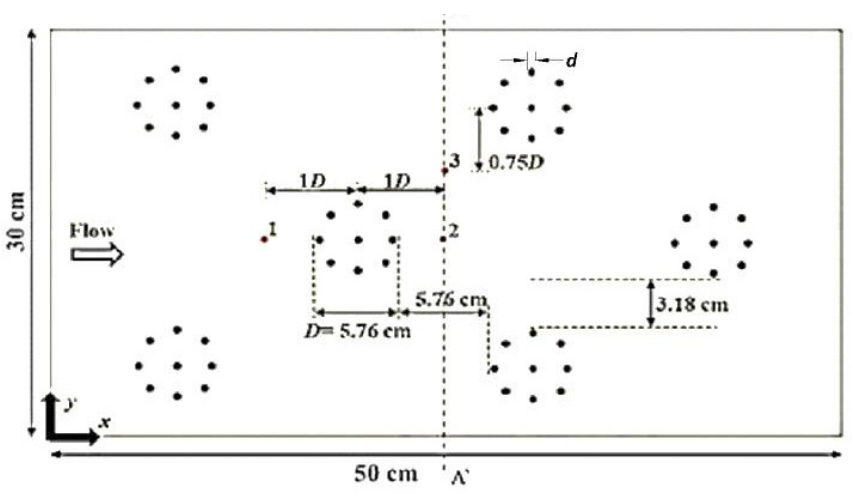

(a)

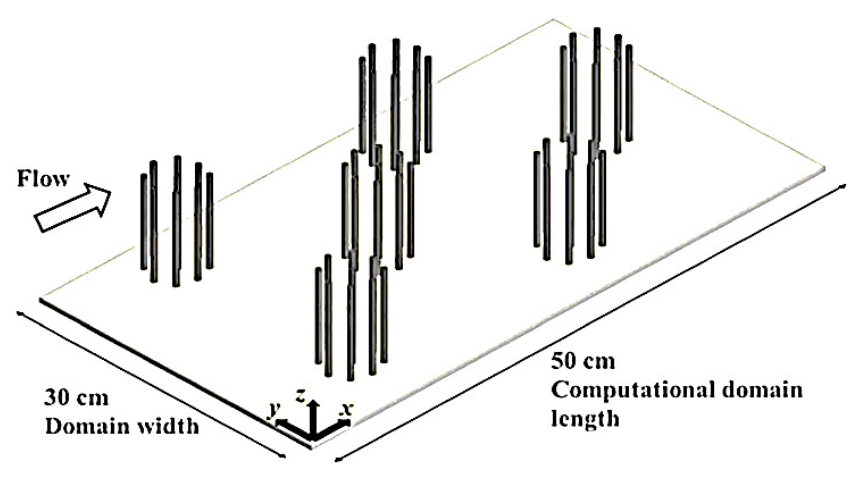

(b)

Fig. 1. (a, b) Schematic representation of the experimental model (Ali et al., 2018).

\subsection{Governing equations for numerical model}

Numerical modeling for steady and incompressible flow ( $p=$ constant) was accomplished using Reynold average Navier Stokes (RANS) and continuity equations. As flow is steady and $p=$ constant therefore, $\frac{D p}{\partial t}=0$. The simplified form of RANS and continuity equation can be stated as follows:

$\frac{\partial u_{i}}{\partial \mathrm{x}_{\mathrm{i}}}=0$

The Navier-Stokes equation for incompressible flow:

$\frac{d u_{i}}{d t}+u_{j} \frac{d u_{i}}{d x_{j}}=-\frac{1}{\varrho} \frac{\partial p}{\partial \mathrm{x}_{\mathrm{i}}}+g_{i}+v \nabla^{2} u_{i}$

The variables used in the equation represent the following: $t=$ time,

$u=$ fluid velocity,

$P=$ fluid pressure,

$\rho=$ fluid density, $v=$ kinematic viscosity

$\nabla^{2}=$ Laplacian operator.

The simplified relation for transport of Reynolds stresses is represented by the following Equation (3).

$\frac{\partial R_{i j}}{\partial t}+C_{i j}=P_{i j}+D_{i j}-\varepsilon_{i j}+\prod_{i j}+\Omega_{i j}$

where

$R_{i j}=$ rate change of Reynolds stresses,

$C_{i j}=$ transport of convection,

$P_{i j}=$ production rate of Reynolds stresses,

$D i j=$ transport of stresses by diffusion,

$\varepsilon_{i j}=$ rate of dissipation of stresses,

$\prod_{i j}=$ stresses transport,

$\Omega_{i j}=$ transport of stresses because of rotation.

The boundary conditions are attained using the turbulent kinetic energy (TKE) equation for Reynolds stresses. The general form of the equation is written as:

$\frac{\partial}{\partial t}(\rho k)+\frac{\partial}{\partial x_{i}}\left(\rho k u_{i}\right)=$

$\frac{\partial}{\partial x_{j}}\left[\left(\mu+\frac{\mu_{t}}{\sigma_{k}}\right) \frac{\partial k}{\partial x_{j}}\right]+\frac{1}{2}\left[P_{i i}+G_{i i}\right]-\rho \varepsilon\left(1+2 M_{t}^{2}\right)+S_{k}$

where $k$ represents kinetic energy tensor, $\varepsilon$ shows the rate of dissipation, $\mu_{t}$ is turbulent viscosity, $\sigma_{k}=0.82$, and $S_{k}$ is source term.

Tensor for kinetic energy (k) can be expressed as:

$k=\frac{1}{2} \overline{u_{i}^{\prime} u_{i}^{\prime}}$

Following Equation (6) represents the rate of dissipation $(\varepsilon)$ as:

$\frac{\partial}{\partial t}(\rho \varepsilon)+\frac{\partial}{\partial x_{i}}\left(\rho \varepsilon u_{i}\right)=\frac{\partial}{\partial x_{j}}\left[\left(\mu+\frac{\mu_{t}}{\sigma_{\varepsilon}}\right) \frac{\partial \varepsilon}{\partial x_{j}}\right] C_{\varepsilon 1} \frac{1}{2}\left[P_{i i}+C_{\varepsilon 3} G_{i i}\right] \frac{\varepsilon}{k}-$

$C_{\varepsilon 2} \rho \frac{\varepsilon^{2}}{k}+S_{\varepsilon}$

The variables used in the equation represent the following: $\sigma_{\varepsilon}=1.0, C_{\varepsilon 1}=1.44, C_{\varepsilon 2}=1.92, S_{\varepsilon}$ represent source term, $C_{\varepsilon 3}$ expressed as a function of flow direction with respect to gravitational vector. $C_{\varepsilon 3}$ is estimated with the help of the following equation:

$C_{\varepsilon 3}=\tanh \left|\frac{v}{u}\right|$

where $v$ shows the flow velocity component similar to the gravitational vector, and $u$ represents the flow velocity component perpendicular to the gravitational vector. 
The turbulent viscosity can be expressed as:

$\mu_{t}=\rho C_{\mu} \frac{k^{2}}{\varepsilon}$

where, $C_{\mu}=0.09$.

\subsection{Numerical model and boundary conditions}

For numerical modeling, the meshing of the channel with its actual longitudinal dimension will result in a very large mesh size that will require large computational time and high computational costs; therefore, a reduced length of the experimental flow domain was considered for simulation purposes. For these reasons, only $1 \mathrm{~m}$ length of the flow domain was considered in the numerical model. It was accomplished by applying periodic boundary conditions at the inlet and outlet of the flow domain. The other dimensions of the experimental flow domain, such as depth and width, were kept unchanged in the numerical simulation work. The circular vegetation patches were introduced in such a way that their densities vary in the streamwise direction. The vegetation was modeled as solid circular rods.

The geometry of the flow domain was first created in the Ansys Workbench. A tri-pave unstructured mesh with tetrahedral mesh elements was used for meshing the flow domain. The nodes for the mesh were $210 \times 160 \times 50$ along the longitudinal, lateral, and vertical directions. It resulted in 1.68 million grid points. The various boundary conditions employed in this simulation work include (i) no-slip wall boundary condition was employed at channel sidewalls, bed of the channel and surfaces of rigid vegetation cylinders, (ii) the top of the channel representing the free surface was specified with symmetry boundary condition, (iii) periodic conditions were assigned at the inlet and outlet faces of the channel to represent the translational periodicity (uniformity). Semi-Implicit Method for Pressure Linked Equations (SIMPLE) algorithm was employed to attain the pressure-velocity coupling. The standard wall function and standard values were utilized for under relaxation factor and near-wall treatment, respectively. Reynold Stress Model (RSM), a 7-equation model, was selected for the turbulence closure. The solution was assumed to be converged after reaching the convergence criteria of $1 \times 10^{-6}$ for all the residuals, i.e. continuity, velocity, turbulence parameters and Reynolds stresses. A mesh independence test was carried out to corroborate the CFD simulation quality. The velocity variation due to mesh refinement was around $1-2 \%$, which showed the mesh independence of the model. The comparison of experimental and numerical results was made to validate the numerical model. The validation of the numerical results was performed for emergent sparse vegetation arrangement.

The validation was attained by comparing the simulated normalized longitudinal velocities at critical positions (as shown in Figure 1(a)) with the experimental data. The experimental data was observed at three Positions. The longitudinal velocity at the downstream of the patch (Position-2) was observed lower than Position-3 because Position-3 is located in a free stream region having no vegetation obstruction. Due to the flow-vegetation interaction, the impact of turbulence yields little difference between the experimental and numerical results near the bed and around the top of vegetation. The validation results are shown in Figure 2, which shows that the numerical results are very close to experimental data, thus showing the reliability of the numerical model for such cases.

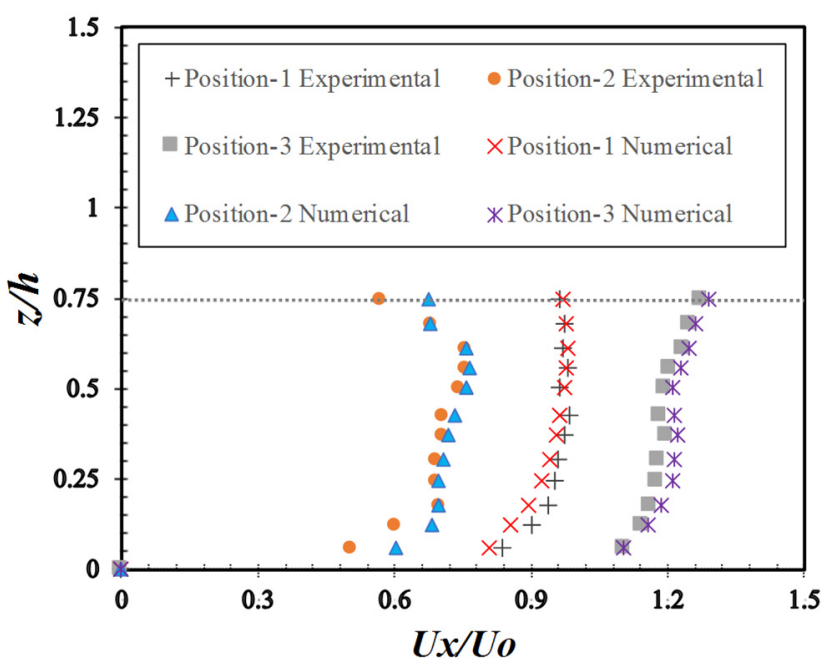

Fig. 2. Validation of numerical model.

\section{VEGETATION CASES FOR NUMERICAL SIMULATION}

This research aims to study the influence of vegetation patch density variation on the flow features. In this study, a model was constructed with the length and width of the channel as $1 \mathrm{~m}$ and $0.3 \mathrm{~m}$, respectively. The channel carried three circular patches of diameter $(D) 5.76 \mathrm{~cm}$ with different densities. These circular patches with variable densities were arranged in a series along the flow direction. Takemura and Tanaka (2007) had proved in their study that flow structure differs by changing the $L / d$ and $G / d$ arrangement of vegetation elements. The patches were bifurcated as sparse and dense for higher and lower ratios of $L / d$, where $L$ represents the spacing between adjacent cylinders, $d$ represents the diameter of a vegetation element, and $G$ represents the spacing between the elements in a cross-stream direction (Figure 3(e)). In the current scenario, the $L / d$ ratio for sparse, intermediate and dense patch was calculated as 3,1.35 and 0.35 . The spacing between the patches was kept equal to the diameter $(D)$ of the patch. The study was conducted with four cases to understand the impact of patch density on flow behavior.

In the first case (Case-A), three vegetation patches were arranged with increasing patch density along the flow direction. A clear gap of $1 \mathrm{~cm}$ was maintained between the patches while the patches were in emergent flow condition. In the second case (Case-B), the patches were arranged in the same pattern as Case-A but in a submerged flow condition. In the third case (Case-C), only two patches were considered with a clear gap of $L_{a} / D=3$ in emergent flow condition. In the fourth case (Case$\mathrm{D})$, patches were arranged in the same pattern as Case-C, but a submerged flow condition was considered for flow vegetation interaction. Different hydraulic conditions for these four cases have been described in Table 2. The model sketches are shown in Figure 3. The simulated vegetation pattern is repeated again and again along the channel length both on the upstream and downstream side and one such pattern has been considered to model the flow features along the channel. In the presence of vegetation, the flow features were investigated at the specific locations $(1,2,3, \ldots ., 7)$ as shown in Figure 3. Ghani et al. (2019b), and Dieter et al. (2014) also conducted the study of various flow properties at these locations at upstream and downstream of the patches for different arrangements. 
Table 2. Hydraulic parameters, where $d$ and $D$ represent the diameter of vegetation element and circular patches, respectively, $h$ is the height of vegetation element, flow depth is represented by $z$, discharge is represented by $Q$, frontal area per volume is represented by ' $a$ ', a number of elements per patch area by $n, a D$ is flow blockage, $U_{o}$ is the mean velocity $(U=Q / A), R_{e}$ represents the Reynolds number for flow $\left(R_{e}=U z / v\right), R_{e} *$ is the Reynolds number for cylinder $\left(R_{e}^{*}=U d / v\right)$, and $F_{r}$ is the Froude number.

\begin{tabular}{|c|c|c|c|c|c|c|c|c|c|c|c|c|c|c|c|c|c|c|c|}
\hline \multirow{2}{*}{ Case } & \multirow{2}{*}{$\begin{array}{c}D \\
(\mathrm{~cm})\end{array}$} & \multirow{2}{*}{$d(\mathrm{~cm})$} & \multirow{2}{*}{$L_{a} / D$} & \multirow{2}{*}{$\begin{array}{c}h \\
(\mathrm{~cm})\end{array}$} & \multicolumn{3}{|c|}{$n\left(\mathrm{~cm}^{-2}\right)$} & \multicolumn{3}{|c|}{$a=n d\left(\mathrm{~m}^{-1}\right)$} & \multicolumn{3}{|c|}{$\begin{array}{l}\text { Flow blockage } \\
\qquad(a D)\end{array}$} & \multirow{2}{*}{$\begin{array}{c}z \\
(\mathrm{~cm})\end{array}$} & \multirow{2}{*}{$\underset{(\mathrm{L} / \mathrm{s})}{Q}$} & \multirow{2}{*}{$\begin{array}{c}U_{o} \\
(\mathrm{~m} / \mathrm{s})\end{array}$} & \multirow{2}{*}{$F_{r}$} & \multirow{2}{*}{$R_{e}$} & \multirow{2}{*}{$R_{e}{ }^{*}$} \\
\hline & & & & & $\begin{array}{c}\mathrm{u} / \mathrm{s} \\
\text { patch }\end{array}$ & $\begin{array}{l}\text { middle } \\
\text { patch }\end{array}$ & $\begin{array}{c}\mathrm{d} / \mathrm{s} \\
\text { patch }\end{array}$ & $\begin{array}{c}\mathrm{u} / \mathrm{s} \\
\text { patch }\end{array}$ & $\begin{array}{l}\text { middle } \\
\text { patch }\end{array}$ & $\begin{array}{c}\mathrm{d} / \mathrm{s} \\
\text { patch }\end{array}$ & $\begin{array}{c}\mathrm{u} / \mathrm{s} \\
\text { patch }\end{array}$ & $\begin{array}{c}\text { middle } \\
\text { patch }\end{array}$ & $\begin{array}{c}\mathrm{d} / \mathrm{s} \\
\text { patch }\end{array}$ & & & & & & \\
\hline A & 5.76 & 0.64 & 1 & 8 & 0.23 & 0.65 & 0.96 & 14 & 42 & 61 & 0.8 & 2.4 & 3.54 & 6 & 9 & 0.501 & 0.653 & 29940 & 3193 \\
\hline B & 5.76 & 0.64 & 1 & 8 & 0.23 & 0.65 & 0.96 & 14 & 42 & 61 & 0.8 & 2.4 & 3.54 & 15 & 9 & 0.200 & 0.413 & 29880 & 1275 \\
\hline $\mathrm{C}$ & 5.76 & 0.64 & 3 & 8 & 0.23 & No patch & 0.96 & 14 & No patch & 61 & 0.8 & No patch & 3.54 & 6 & 9 & 0.501 & 0.653 & 29940 & 3193 \\
\hline
\end{tabular}

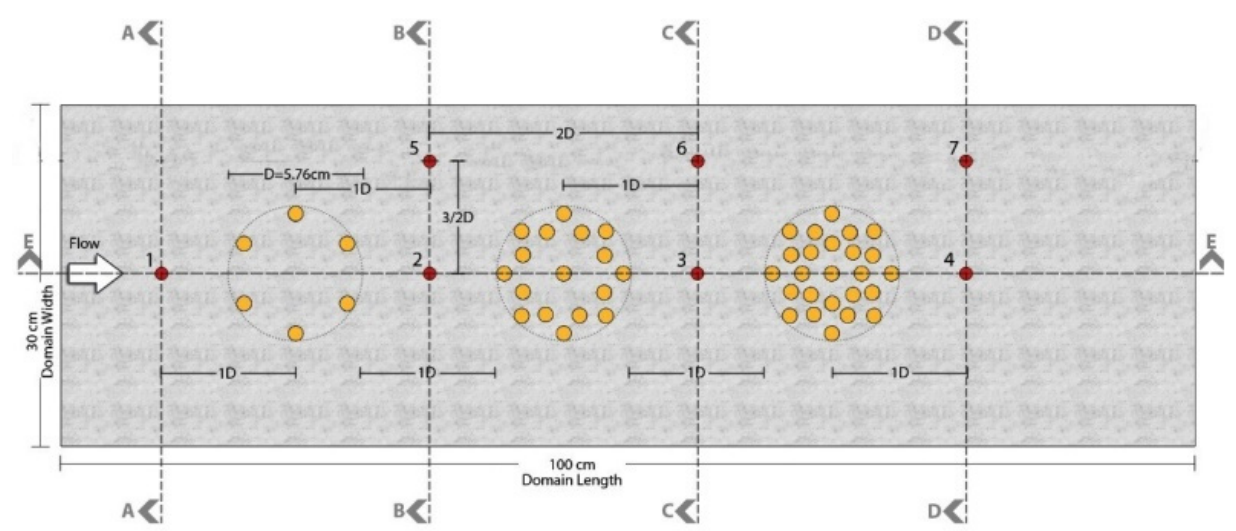

(a)

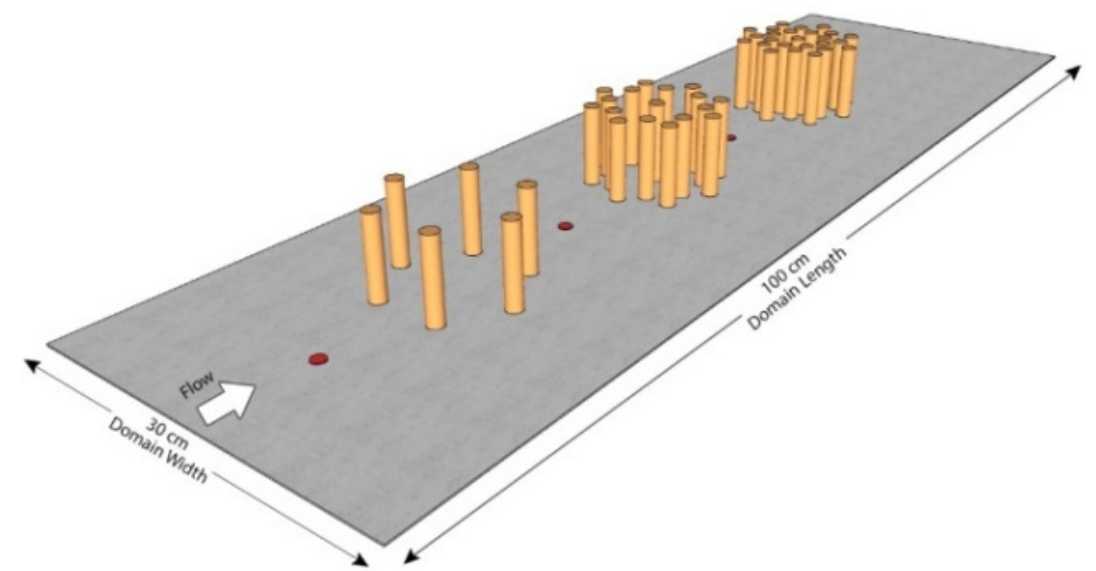

(b)

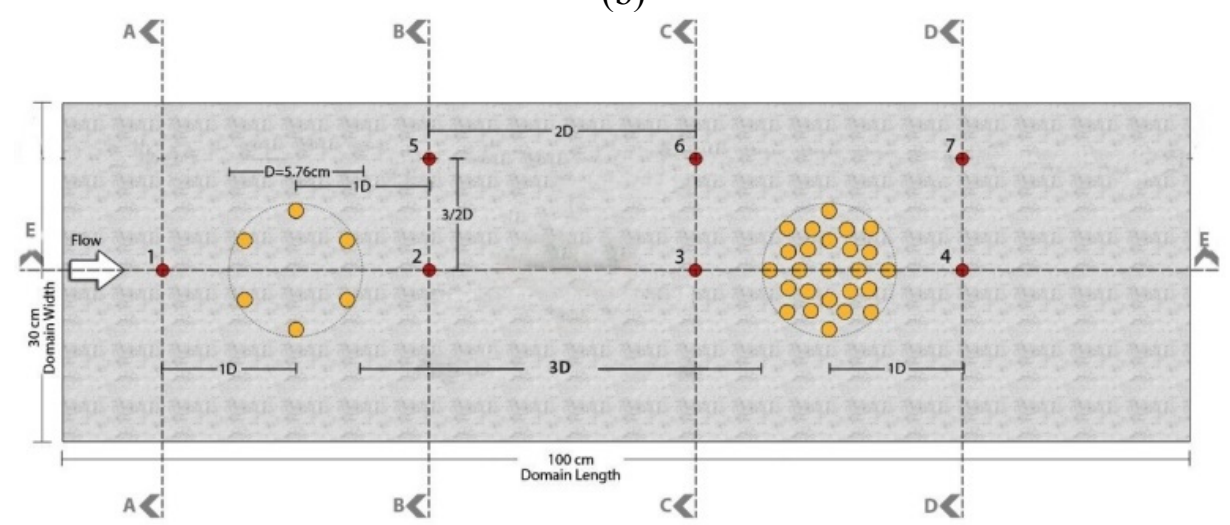

(c) 


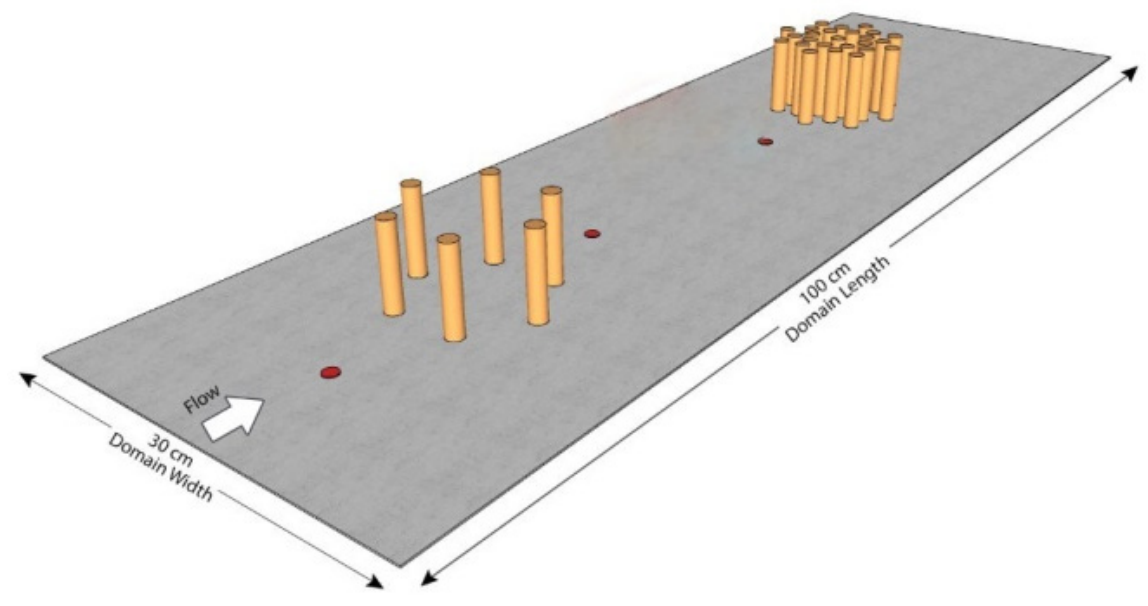

(d)

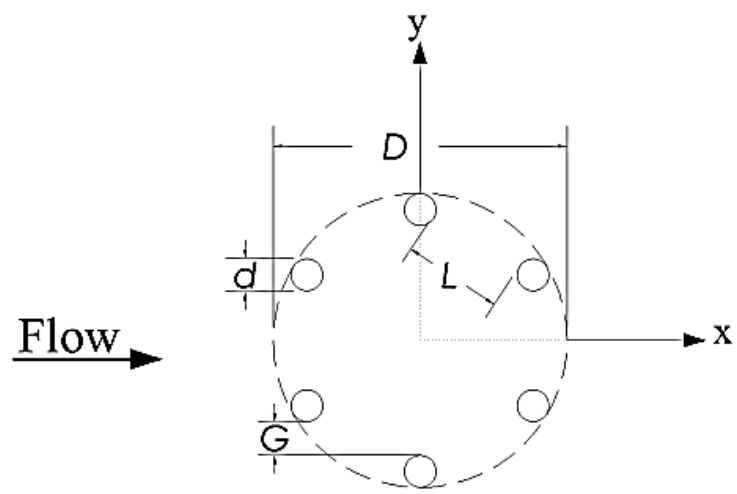

(e)

Fig. 3. Schematic diagram of flow domain; $(\mathrm{a}-\mathrm{b})$ represent cases $(\mathrm{A}-\mathrm{B})$ and $(\mathrm{c}-\mathrm{d})$ represents cases $(\mathrm{C}-\mathrm{D})$ with measurement locations (i.e $1,2,3, \ldots, 7)$, (e) represents various vegetation patch parameters.

\section{RESULTS AND DISCUSSION \\ 4.1 Velocity distribution}

4.1.1 Streamwise velocity $\left(U_{x}\right)$

The effect of density variation showed a considerable difference in mean streamwise velocities $\left(U_{x}\right)$. Experimental analysis of various researches indicated that the flow behavior changed near the vegetation patch. Therefore, it was found necessary to analyze the flow features at different locations, i.e. upstream, downstream and at some points adjacent to the patches ( $\mathrm{Li}$ et al., 2019). Takemura and Tanaka (2007) has explained the significance of the observing locations for flow features. The mean longitudinal velocities $\left(U_{x}\right)$ were normalized with mean velocity $\left(U_{o}\right)$, and flow depth $(z)$ was normalized with height of vegetation $(h)$. The critical points for the measurement of flow features are shown in Figure 3(a-d).

The results gathered for all four cases showed a significant reduction in normalized streamwise velocity (shown in Figure $4 a(i))$. The velocity at the $\mathrm{u} / \mathrm{s}$ and $\mathrm{d} / \mathrm{s}$ of the upstream patch (Position-1 and Position-2) was consistent as the upstream patch was sparse and offered less resistance to the flow. The upstream patch had a negligible effect on the flow velocity. The presence of wider spaces among the vegetation elements of the upstream patch generated turbulent jet at the exit, which resulted in very small inflation of the normalized streamwise velocities $\left(U_{x}\right)$ when compared with mean velocity $\left(U_{o}\right)$ at Position-1 and Position-2 (Rajaratnam, N., 2006). In Case-A and Case-B, the flow that passed through the upstream patch was directly obstructed by two more dense patches with flow blockages $(a D)$ of 2.4 and 3.54 successively arranged in line with clear spacing equal to diameter $(D)$ of the patch. However, in Case-C and Case-D, there exists a clear gap $\left(L_{a} / D=3\right)$. The flow after passing through the upstream patch is obstructed by a dense patch of flow blockage $(a D)$ of 3.54 .

The magnitude of velocity at Position- 1 and Position-2 were found to be consistent in Case-A and Case-B. In Case-C, the average value of velocity at Position- 2 was $10.6 \%$ higher than Position-1. A significant variation in the velocity magnitude was observed at Position-3 for all the cases. In Case-A, a 54\% reduction in velocities was observed at Position-3 when compared to Position-1 at the mean depth $(z / h)$ of 0.5 (Figure $4 \mathrm{i}(\mathrm{a})$ ). Whereas, in Case-C, this reduction in streamwise velocities was $12 \%$ (Figure $4 \mathrm{i}(\mathrm{c}))$. The overall velocity reduction at Position- 4 for Case-A was $93.8 \%$. In the absence of the middle patch, the magnitude of velocity for Case-C was $153 \%$ higher at Position3 for depth $(z / h=0.5)$ compared to Case-A. In Case-C, around $83 \%$ velocity reductions were observed at Position- 4 . The presence of vegetation patches offer resistance to the flow, which reduces velocity significantly. However, the flow attained higher velocities affecting the channel capacity when it passed through the vegetation free region. Table 3 shows the longitudinal velocity reductions at three positions for averaged depth $(z / h=0.5)$. Massive flow obstructions in the patches diverted the upstream flow toward sideways, producing higher velocities as there was no direct obstruction in the region (Position-5, Position-6 and Position-7). 
(a)

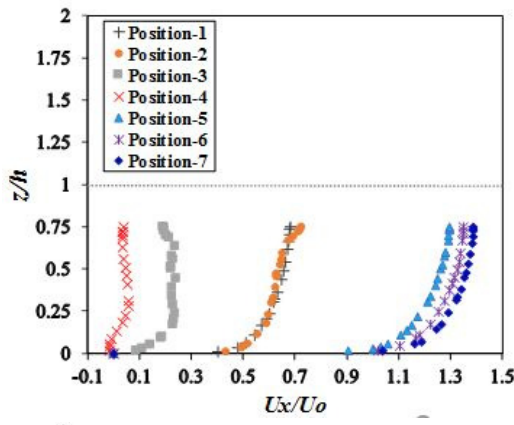

(b)

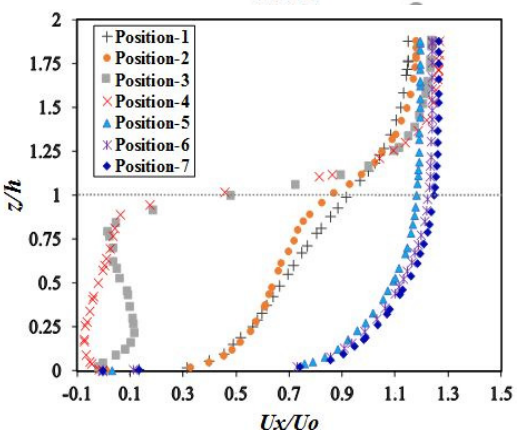

(c)

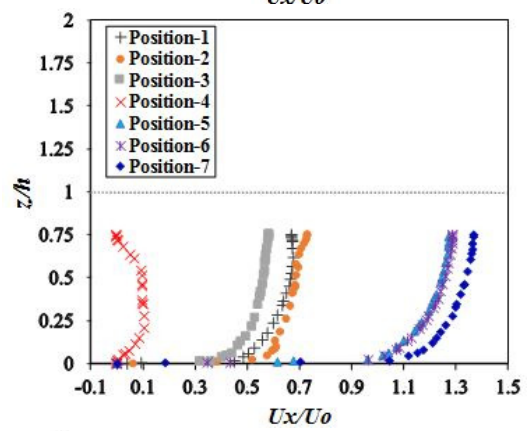

(d)

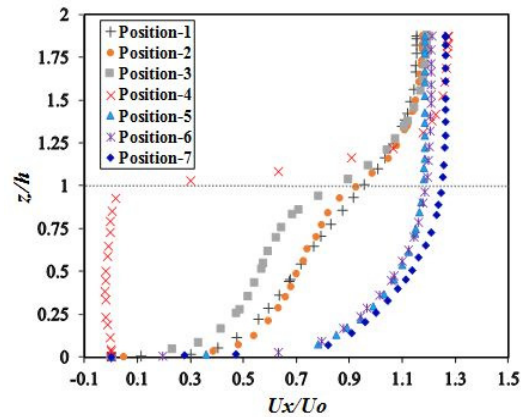

(i)
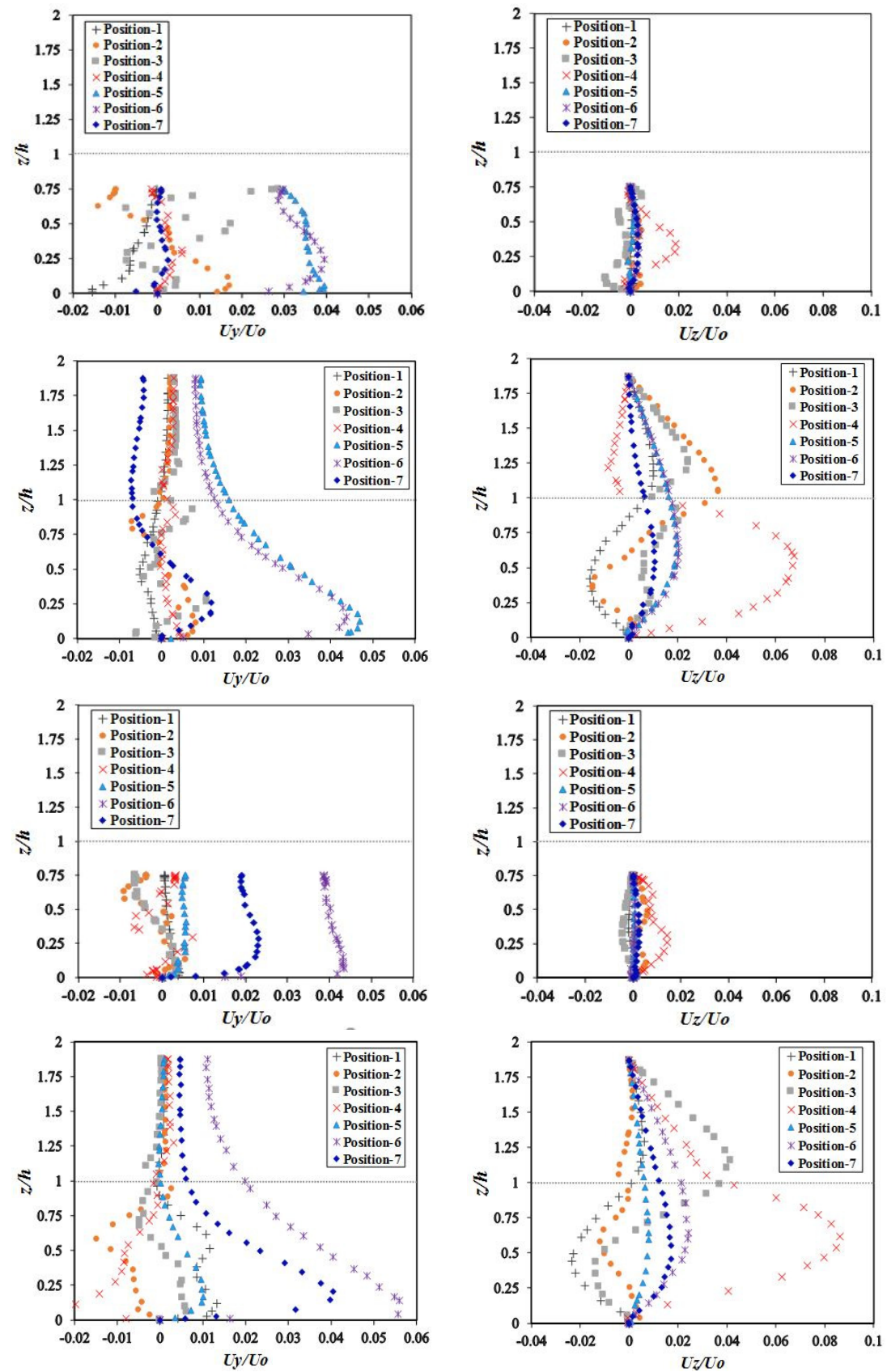

(ii)

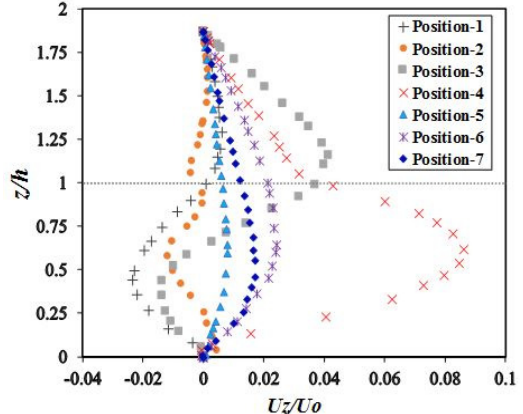

(iii)

Fig. 4. Representation of (i) Streamwise velocity $\left(U_{x}\right)$, (ii) Transverse velocity $\left(U_{y}\right)$, (iii) Depthwise velocity $\left(U_{z}\right)$ at all specified locations for (a) Case-A, (b) Case-B, (c) Case-C and (d) Case-D. The dotted line is showing the top of vegetation.

Table 3. Summary of Longitudinal velocity reduction for different cases.

\begin{tabular}{lccc}
\hline & Longitudinal velocity reduction with respect to initial velocity at $z / h=0.5$ & \\
\hline Case & $\begin{array}{l}\text { Downstream of first } \\
\text { patch (Position-2) }\end{array}$ & $\begin{array}{l}\text { Downstream of middle } \\
\text { patch (Position-3) }\end{array}$ & $\begin{array}{l}\text { Downstream of last } \\
\text { patch (Position-4) }\end{array}$ \\
\hline Case-A & $22.73 \%$ & $53.80 \%$ & $93.80 \%$ \\
Case-B & $69.84 \%$ & $73.01 \%$ & $99.93 \%$ \\
Case-C & $27.87 \%$ & $11.83 \%$ & $83.01 \%$ \\
(Without Middle Patch) & $72.47 \%$ & $65.43 \%$ & $106.85 \%$ \\
Case-D & & & \\
(Without Middle Patch) & & & \\
\hline
\end{tabular}

\subsubsection{Transverse velocity $\left(U_{y}\right)$}

Figure 4ii(a-d) illustrates the transverse velocity $\left(U_{y}\right)$ profiles at all the desired positions for the four cases. The plots are drawn between the normalized cross streamwise velocities
$\left(U_{y} / U_{o}\right)$ and normalized depth $(z / h)$. It can be observed that the magnitudes of the cross streamwise velocities are minimal (approximately zero or negative) in contrast with the streamwise $\left(U_{x}\right)$ velocities. 
It can be perceived from the plots of normalized transverse velocities $\left(U_{y} / U_{o}\right)$ that Position-3 showed more fluctuation than any other Position for Case-A and Case-B. Similarly, significant fluctuations were observed at Position-4 for Case-C and Case-D (Figure 4ii(a-d)). This oscillation in the profile is because of obstruction offered by vegetation, which diverted the flow in the orthogonal direction. Furthermore, high transverse velocities $\left(U_{y}\right)$ were seen in the free stream area adjacent to the patches. As the increase in vegetation densities resists the flow largely and diverts it laterally, it increases mean velocities in the neighboring areas and reduces velocities at the downstream of the patch in the wake (Wang et al., 2019; Zong and Nepf, 2011). However, at Position-1 and Position-4, the transverse velocities were very small to nearly zero and negative. In Cases A and B at Position-2 and Position-3, huge diversion of cross streamwise velocities was observed due to the existence of patches having flow blockage $(a D) 0.8$ and 2.4, which resulted in higher fluctuations. However, in Case-C (Figure 4ii(c)), higher fluctuations were observed due to the existence of dense patch with flow blockage $(a D)$ of 3.54 .

\subsubsection{Depthwise velocities $\left(U_{z}\right)$}

The simulated vertical velocities $\left(U_{z}\right)$ were normalized with mean velocity $\left(U_{o}\right)$, and the graphs have been plotted against normalized depth $(z / h)$. The magnitude of vertical velocities was also obsereved to be very small similar to transverse velocities. Figure 4iii $(\mathrm{a}-\mathrm{d})$ describes the depthwise velocity $\left(U_{z}\right)$ distributions at all the points of concern for the emergent and submerged vegetation arrangements.

At Position-4, huge fluctuations were observed for all the cases as shown in Figure 4iii(a-d). These fluctuations are due to turbulence, larger density and greater flow blockage $(a D)$ indicating the upward movement of flow. However, minute fluctuations were observed at the remaining positions. In submerged vegetation cases, the peaks of the vertical velocities $\left(U_{z}\right)$ were clearly noticed, which was also analyzed by BarriosPiña et al. (2014) in their numerical exploration. The positive values of vertical velocities $\left(U_{z}\right)$ indicate the rising flow movement, whereas negative values of depthwise velocities $\left(U_{z}\right)$ indicate descending flow (Anjum et al., 2018a; Ghani et al., 2019b; Pasha and Tanaka, 2016; Zhao and Huai, 2016). The upward movement of flow was higher for the submerged vegetation cases (Case-B and Case-D) at the measuring positions. The position adjacent to the vegetation patches showed no significant variation in flow magnitude, as the depthwise velocities were almost zero. However, the descending flow was observed at Position-1 due to the sparse vegetation patch (Figure 4iii(a-d)).

\subsubsection{Velocity contours distribution}

In submerged vegetation case, the flow distributes itself in two layers. The vegetation obstructs one part of the flow in a similar way to emergent vegetation, and it is a slow-moving flow while the other part of the flow is above the top of vegetation, which moves faster than the lower layer (Shucksmith et al., 2010).

The simulated results obtained for the submerged vegetation revealed that velocity reduction in the vegetation zone $(z / h<1)$ is similar to submerged and emergent cases (Figure $4 \mathrm{i}(\mathrm{a}-\mathrm{d})$ ). Figure $4 \mathrm{i}(\mathrm{b}, \mathrm{d})$ shows that the streamwise flow velocity $\left(U_{x}\right)$ is increasing in the layers directly above the patch height $(z / h=1)$ for measuring positions located between vegetation patches. There exists a point of inflection at the top layer of patch $(z / h>$ 1 ) in the exchange zone due to momentum exchange (Nepf and
Vivoni, 2000), which accelerates the streamwise velocities (Figure 4i(b, d)). This exchange zone is noticeable for the flows resisted by vegetation patches (Position-2, Position-3 and Position-4). Anjum et al. (2018a) and Righetti and Armanini (2002) also recognized this variation of flows in the case of submerged vegetation. More hindrance and turbulence were offered by denser patches within the vegetation zone $(z / h<1)$ (Figure 4i(b)). The longitudinal velocity reduction was due to a successive increase in the frontal area per volume and larger flow blockage of the patches in the downstream flow direction. The behavior of velocity was notable at Position-3 for both Case-B and Case-D. The velocity values observed for Case-B were almost $88 \%$ lesser than Case-D, which has been represented in Figure $4 \mathrm{i}(\mathrm{b}, \mathrm{d})$. The phenomenon can be better understood in Figure 5(a-d), showing the primary velocities over the longitudinal sections E-E for all four cases.

The velocity contours show higher velocity magnitude in the clear gap between the vegetation patches for Case-C and CaseD. The increment in vegetation patch density alters the vertical distribution of longitudinal velocity next to the patch. The velocity distribution acquired an S-shape (Figure 4). The range of $\mathrm{S}$-shaped profile varied with the increase in patch densities with flow blockage of 0.8 and 2.4 for Position-2 and Position-3, respectively. For all four cases, the maximum reduction in velocity occurred downstream of the last patch with a flow blockage of 3.54 (Position-4) that diminished the S shape. Li et al., (2018) also concluded this in their experimental work.

For further understanding, the primary velocity contours overlaid by the secondary velocity vectors has been shown at four different cross-sections (Section A-A, Section B-B, Section $\mathrm{C}-\mathrm{C}$ and Section D-D) for all the cases in Figures 6-9. Section A-A (located at a distance of $D / 2$ on the $\mathrm{u} / \mathrm{s}$ of the first patch as marked in Figure 3(a,b)) was selected to observe the flow properties before the interaction with the vegetation patch. From Figure 6, the velocity values were observed to be maximum in regions above the patches because there was no direct hindrance to the flow. In contrast, minimum velocity magnitudes were observed through the vegetation regions. The secondary velocity vectors were merged with the primary velocity contours, which reflect the higher flow velocities on the sides of the vegetation patch (Chen et al., 2012), while dispersed secondary velocity vectors were found at the vegetated region. For Case-A and Case-B, the flow is observed to be moving downward near the sidewalls of the channel represented by secondary velocity vectors. In the first section (section A-A), located at distance $D / 2$ upstream of the first (sparse) patch of Case-A, the flow moved upward directly behind the vegetation patch. This upward movement is due to obstruction offered by vegetation patches. The flow moved from the vegetated (rough) to non-vegetated (smooth region) the downstream of the first patch at section B-B where there is no obstruction. In section C$\mathrm{C}$ and D-D, circulations of secondary velocity vectors were observed close to the bed, near the walls of the channel and near the vegetation region, due to smooth and turbulent flow interactions, which resulted in the formation of swirls (Figure 6(i-iv)) (Ali, 2013).

In case of submerged vegetation (Figure 7), part of the flow was unobstructed and moved above patch height $(z / h>1)$, where velocity is maximum due to the momentum exchange among the upper laying flow and vegetation patches. Therefore, the obstructed flow moved upward towards the relatively smoother region and have also been observed near the vertical walls of the channel. As the maximum velocity reduction was observed on the $\mathrm{d} / \mathrm{s}$ of the last patch $(a D=3.54)$, flow circulations were observed at section D-D around the vegetation patch. 


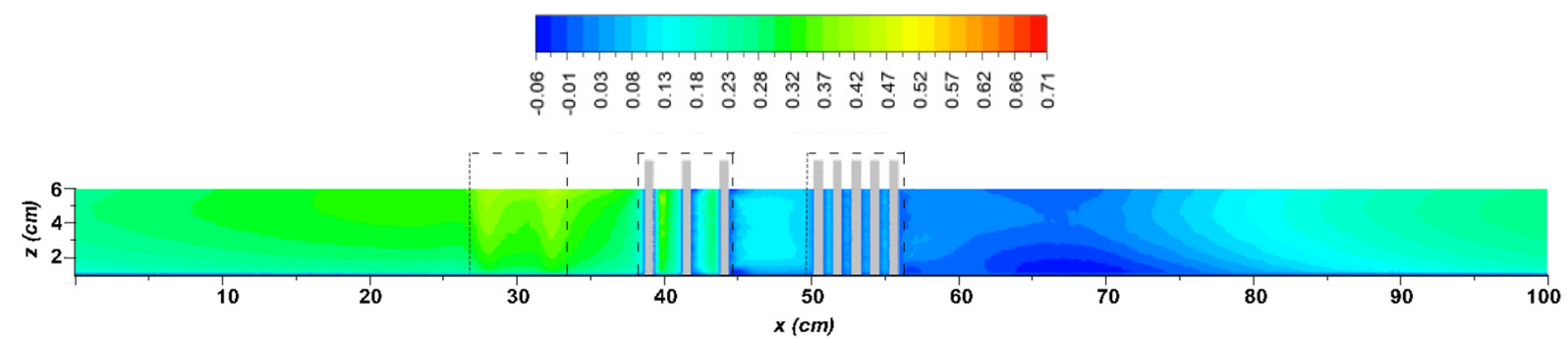

(a) Emergent vegetation

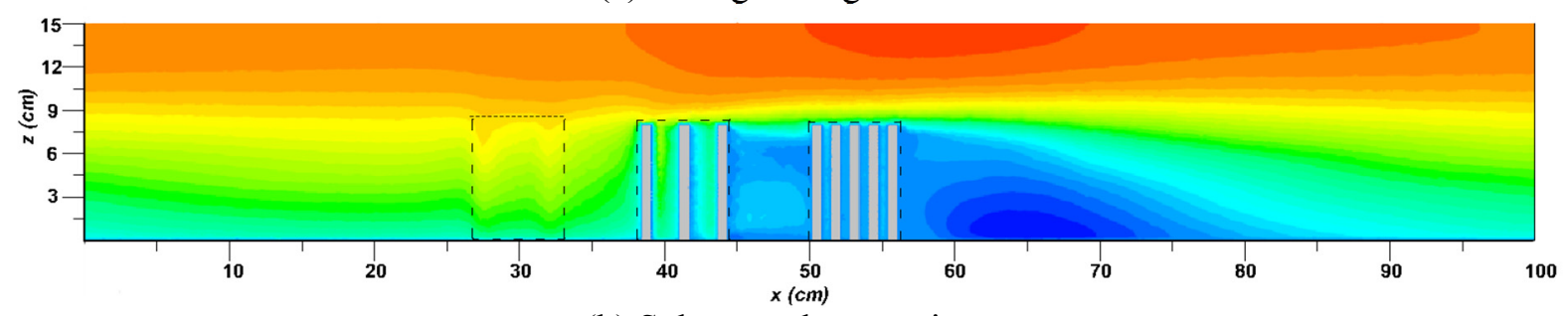

(b) Submerged vegetation

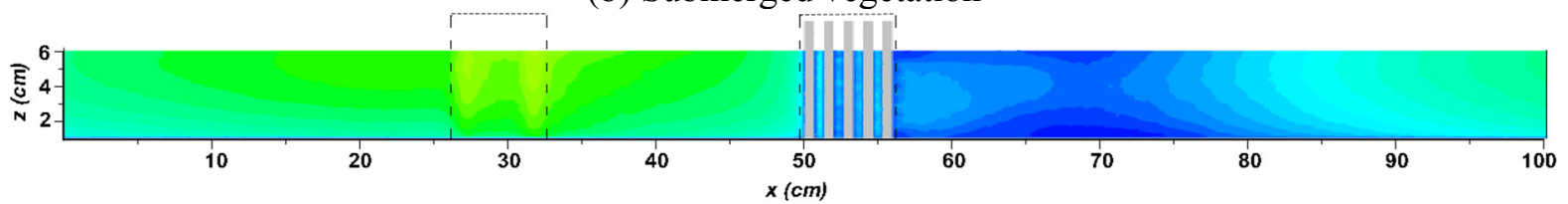

(c) Emergent vegetation without middle patch

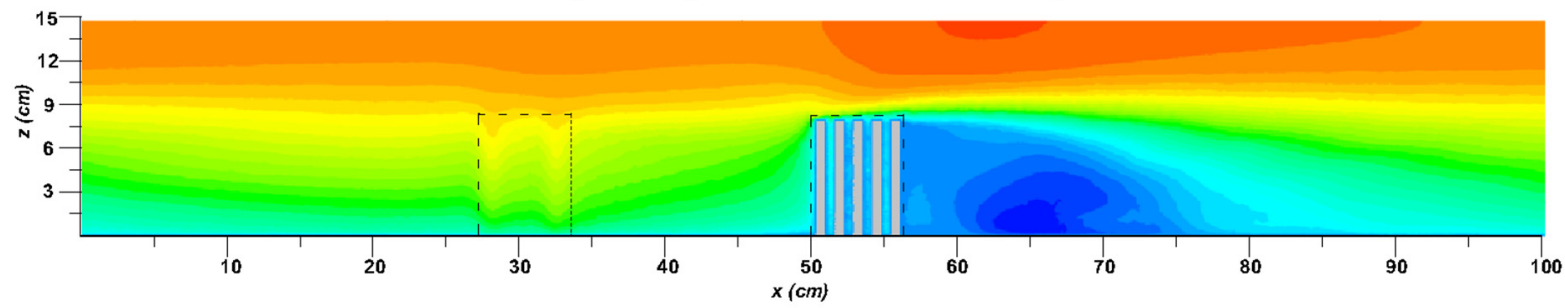

(d) Submerged vegetation without middle patch

Fig. 5. Contour plots of simulated streamwise velocities $\left(U_{x}\right)$ at longitudinal section E-E for (a) Case-A, (b) Case-B, (c) Case-C and (d) Case-D. Section E-E is shown in Figure 3(c).

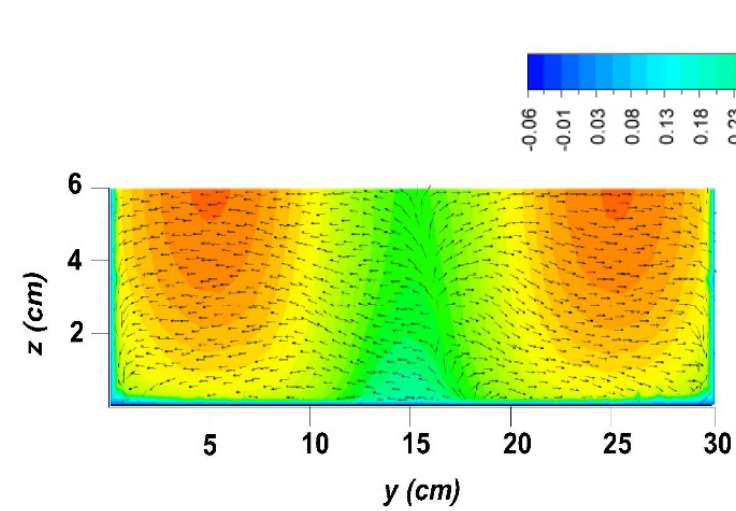

(i) Section: A-A

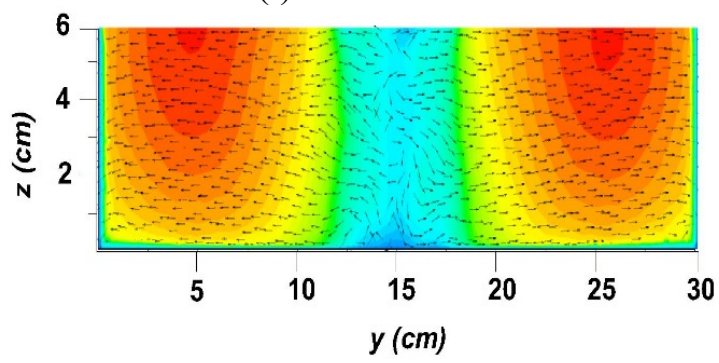

(iii) Section: C-C

Case-A

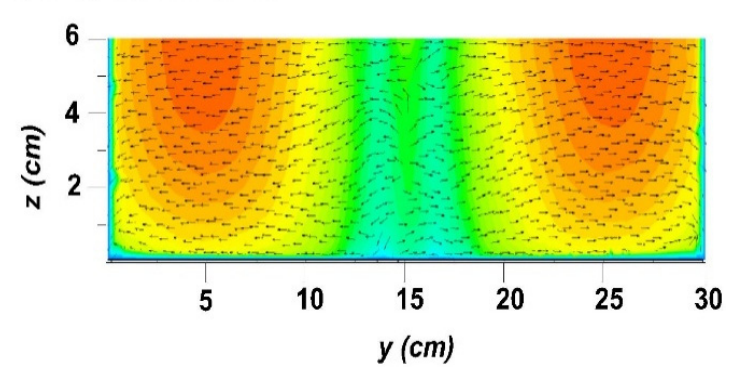

(ii) Section: B-B

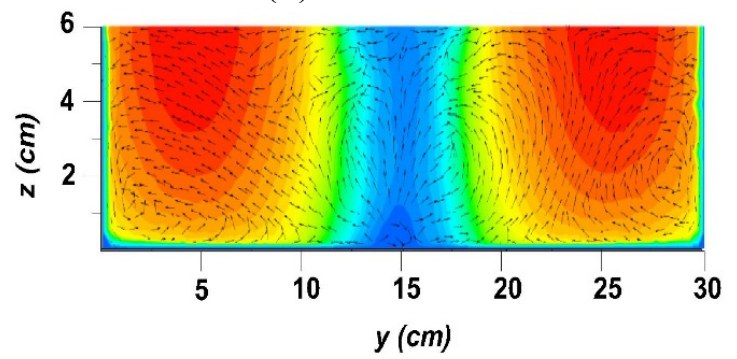

(iv) Section: D-D

Fig. 6. Simulated streamwise velocity contours overlaid by secondary velocity vectors for Case-A at four cross-sections. For cross-sections see Figure 3(a,b). 


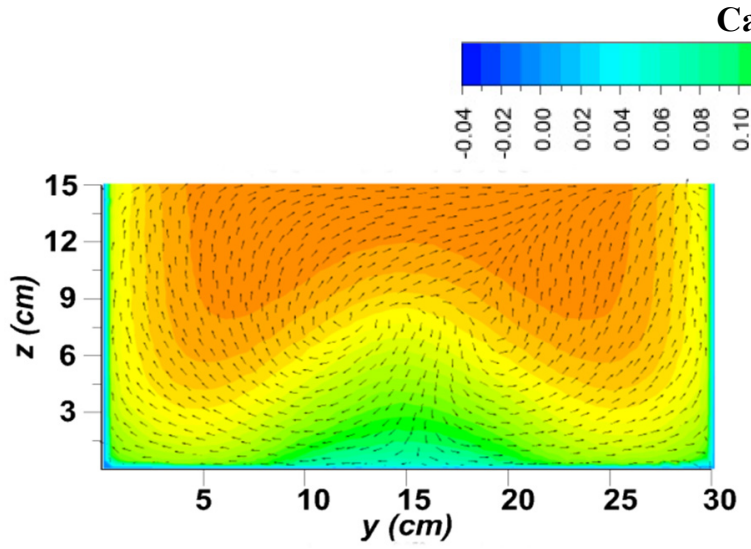

(i) Section: A-A

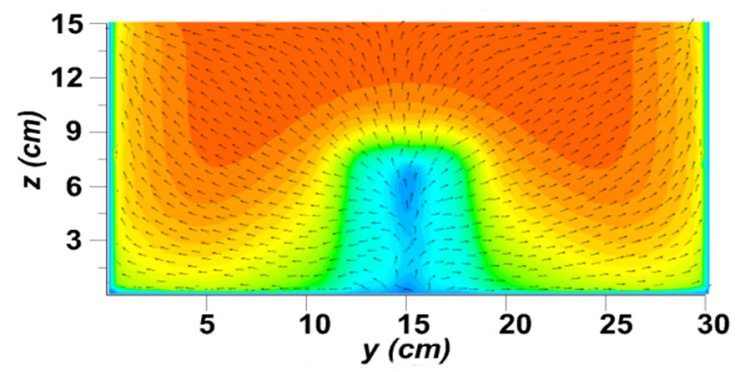

(iii) Section: C-C
Case-B

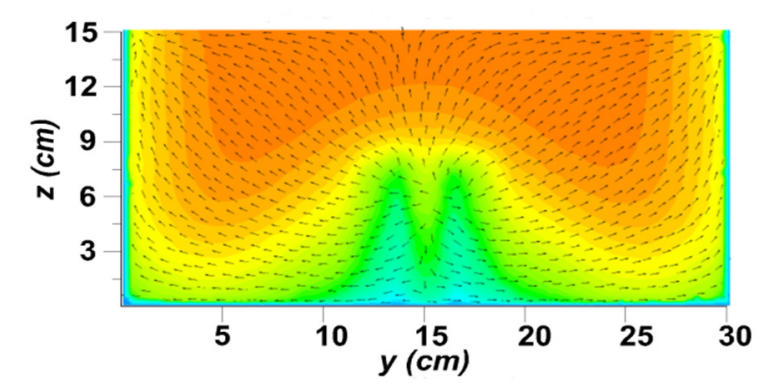

(ii) Section: B-B

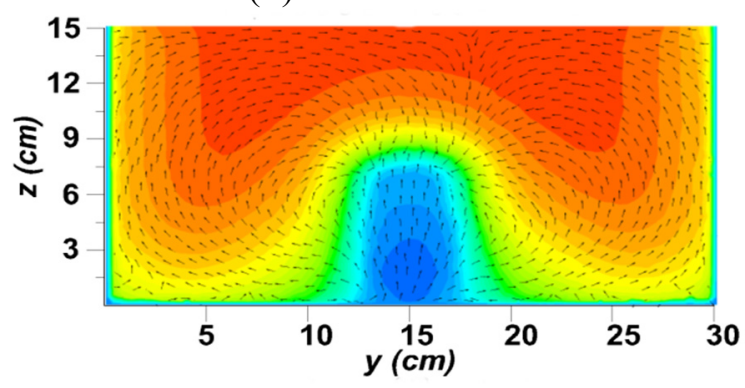

(iv) Section: D-D

Fig. 7. Simulated streamwise velocity contours overlaid by secondary velocity vectors for Case-B at four cross-sections. For cross-sections see Figure 3(a,b).

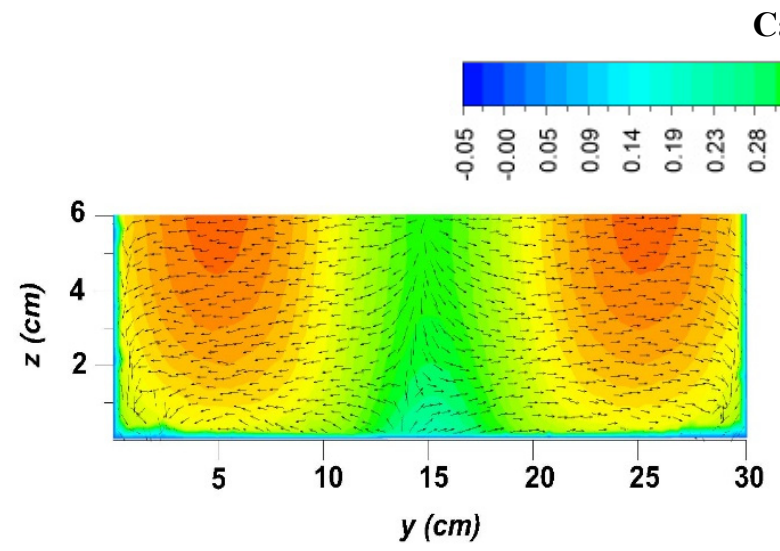

(i) Section: A-A

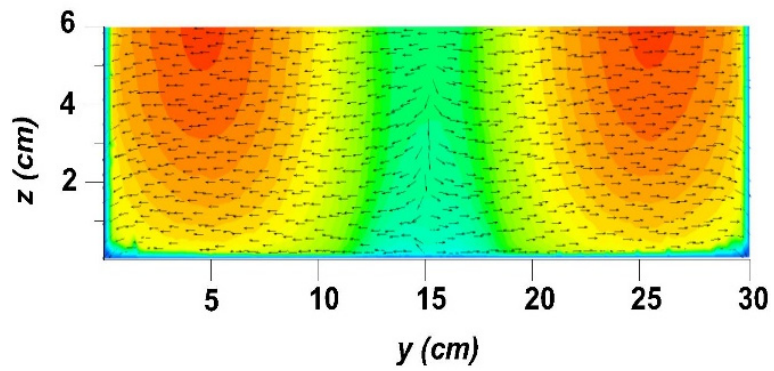

(iii) Section: C-C

\section{Case-C}

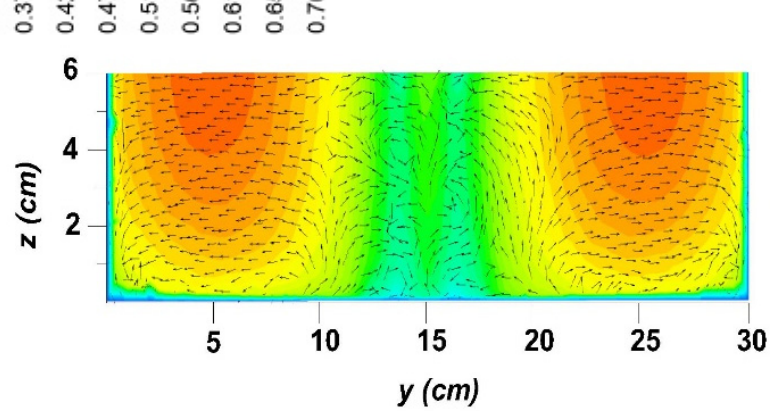

(ii) Section: B-B

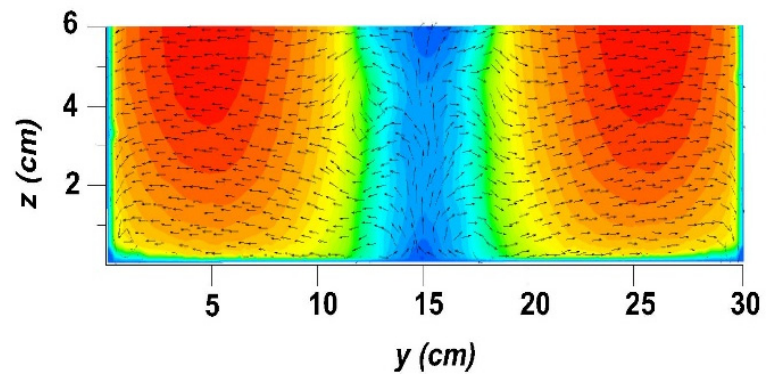

(iv) Section: D-D

Fig. 8. Simulated streamwise velocity contours overlaid by secondary velocity vectors for Case-C at four cross-sections. For cross-sections see Figure 3(a, b).

It has also been noted that in a submerged case, the intensities of secondary cells are less when compared to the emergent case. The primary velocity contours along with secondary cells have been shown in Figure 7(i-iv).
In Case-C, there exists a clear gap $\left(L_{a} / D\right)$ of 3 between the patches. The flow at Section A-A showed downward movement exactly behind the vegetation region and along the vertical sidewalls. The impact of the first patch $(a D=0.8)$ has been 


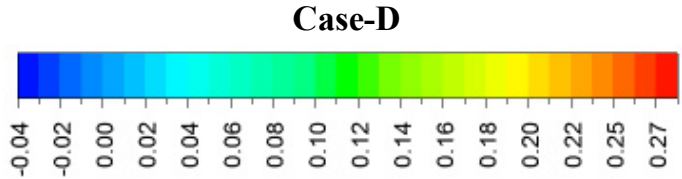

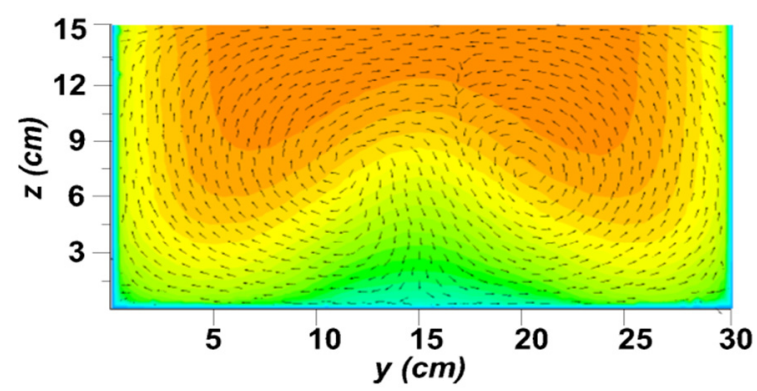

(i) Section: A-A

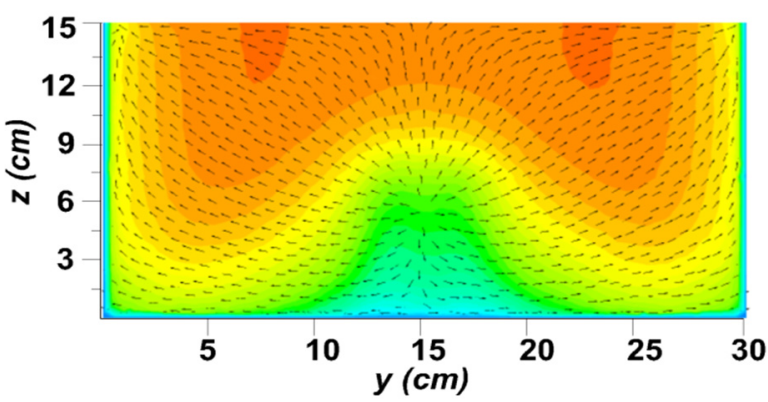

(iii) Section: C-C

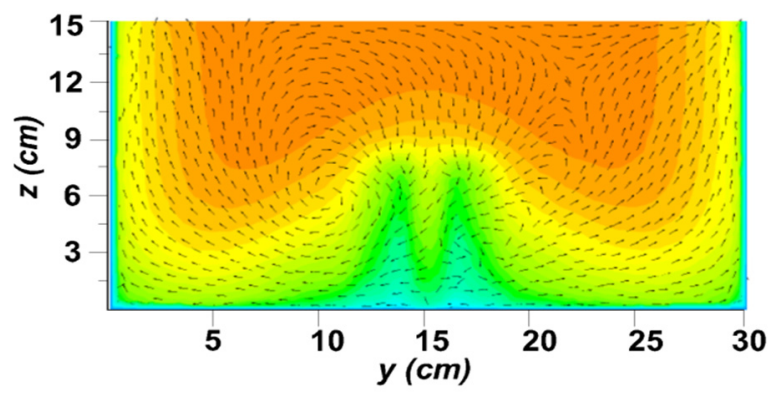

(ii) Section: B-B

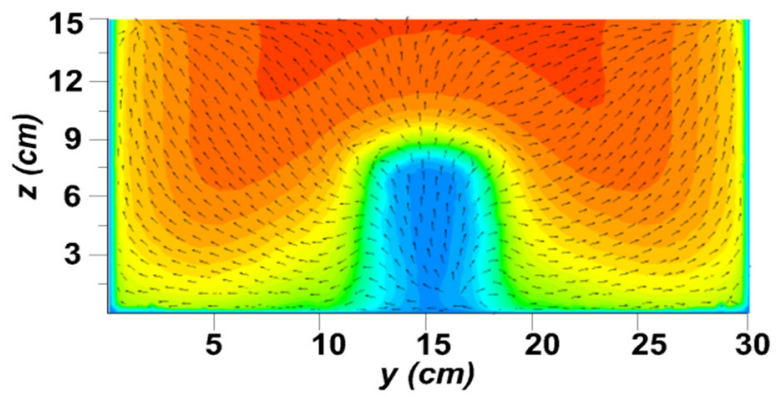

(iv) Section: D-D

Fig. 9. Simulated streamwise velocity contours overlaid by secondary velocity vectors for Case-D at four cross-sections. For cross-sections see Figure 3(a,b).

observed at section B-B. The circulation of secondary cells represented an obstruction in the flow direction, which resulted in an increase of velocity due to the space present between the vegetation elements. The contour plots of primary velocity and secondary vectors have been shown at all sections in Figure 8(i-iv).

The submerged vegetation without a middle patch (Figure 9) has shown circulation near the vegetation region due to the mixing of turbulent flow with the smooth layer of flow above the vegetation height $(z / h>1)$. At the downstream of the first patch, upward flow movement was observed at section C-C due to no direct vegetation resistance. At section $\mathrm{D}-\mathrm{D}$, minute circulations have been seen near the top edge of vegetation elements. The contour plots with velocity vectors at all sections for CaseD is represented in Figure 9(i-iv).

The velocity contours at $z=6$ for all four cases is represented in Figure 10(a-d). These velocity contours along the $x-y$ plane were found to support the understanding of flow behavior and velocity distribution around the vegetation patches. These surfaces have been considered helpful in investigating the wakes generation behind the circular patches. Flow structure is dependent on the $L / d$ arrangement of the vegetation patch. In all the cases (A-D), very minute separation zones were observed behind each vegetation element for $L / d=$ 3 (sparse patch). In Cases A and B, small separation zones developed around each cylindrical element of the intermediate patch that merged with each other. It has been observed that the production of horseshoe vortices around the dense patch $(L / d=$ $0.35)$ merged with the vortices generated by the middle patch $(L / d=1.35)$ due to a smaller clear gap $\left(L_{a} / D\right)$, hence representing a combined extended wake. For Cases C and D, a clear separation zone developed by horseshoe vortices can be noticed around the dense patch $(L / d=0.35)$. For all the cases (A-D), small vortices were formed behind each vegetation element in the sparse patch $(L / d=3)$ which is termed as Primitive Karman vortex street (PKV), however no large-scale vortex streets were generated. These results have also been observed by previous investigators (Goharzadeh and Molki, 2014; Takemura and Tanaka, 2007). Large-scale vortex streets (LKV) were generated the downstream of the dense patch $(L / d=0.35)$ in Figure 10 $(\mathrm{a}-\mathrm{d})$.

\subsection{Turbulent characteristics 4.2.1 Reynolds stress distribution}

The existence of vegetation and boundary resistance result in a complex turbulent flow structure in an open channel flow. The analysis of the turbulent flow features is carried out with the help of Reynolds stresses and other turbulence parameters. To investigate the effect of varying vegetation patch density on the turbulence, the Reynolds stresses were analyzed at the specified locations at the upstream, downstream and on the sides of vegetation patches. To investigate the shear stresses $\left(-u^{\prime} w^{\prime}\right)$ and the normal stresses $\left(u^{\prime} u^{\prime}, v^{\prime} v^{\prime}, w^{\prime} w^{\prime}\right)$, profiles were developed between normalized turbulence stresses and normalized depth of the channel. Reynolds stresses were normalized with mean velocity $\left(U_{o}^{2}\right)$ and depth of flow $(z)$ with a height of vegetation $(h)$ to make these factors unitless. These stresses have been shown in Figure 11 for all four cases. Where $u^{\prime}, v^{\prime}$ 
(a)

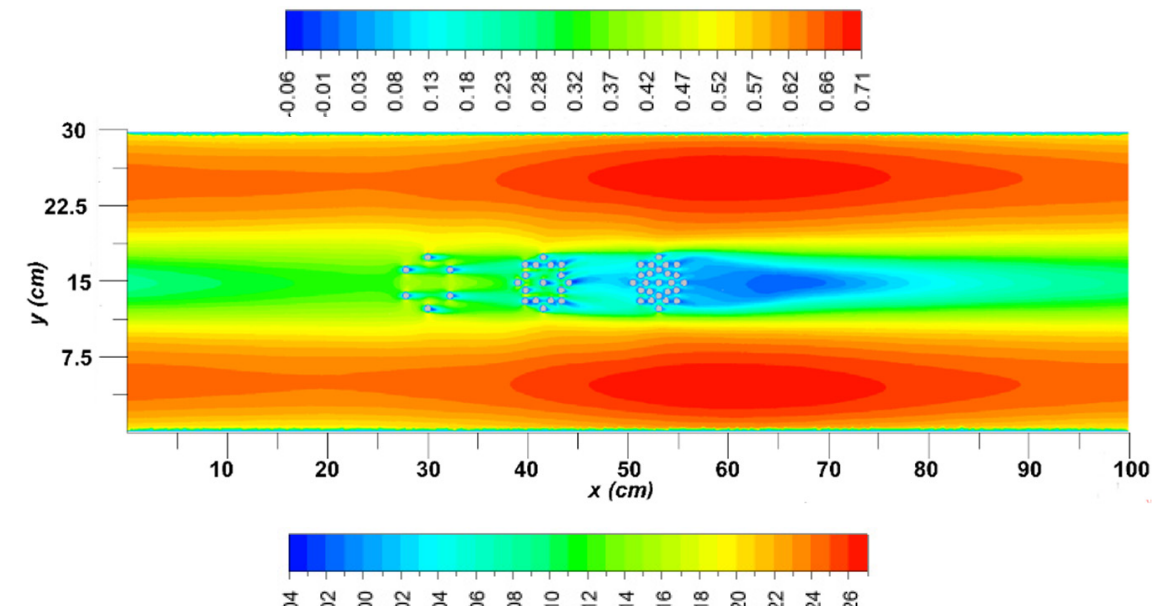

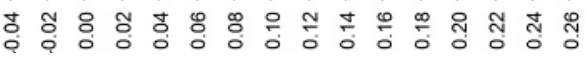

(b)

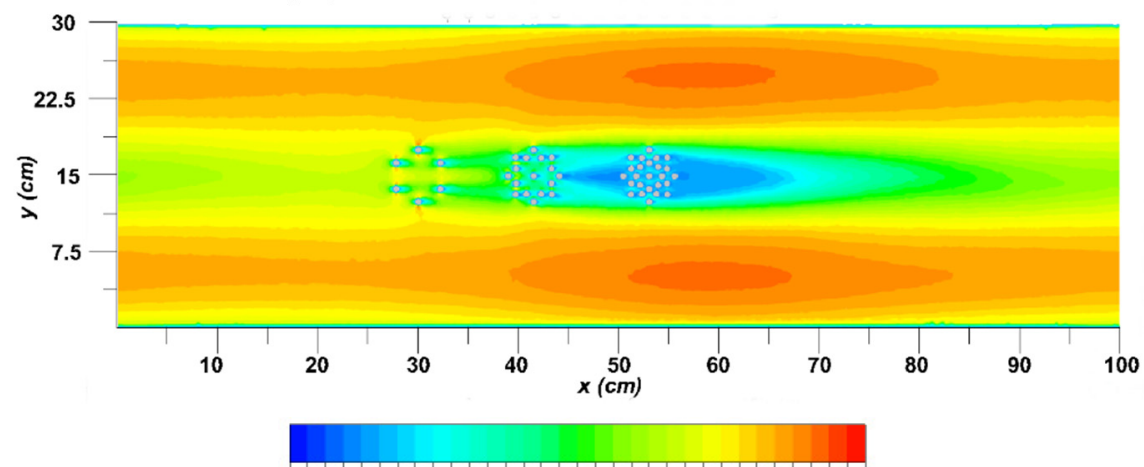

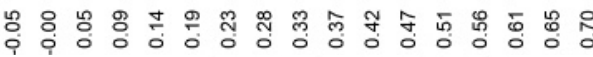

(c)

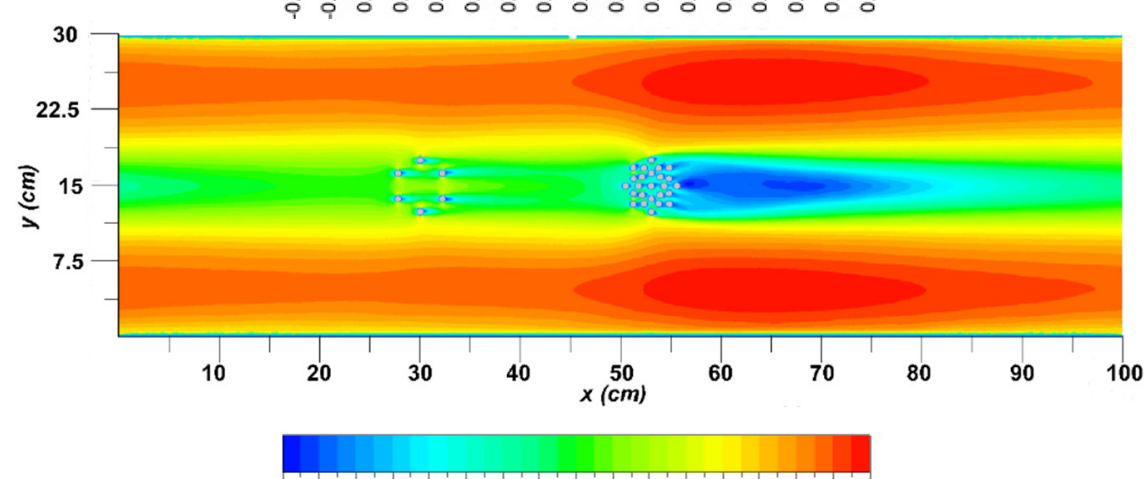

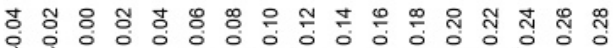

(d)

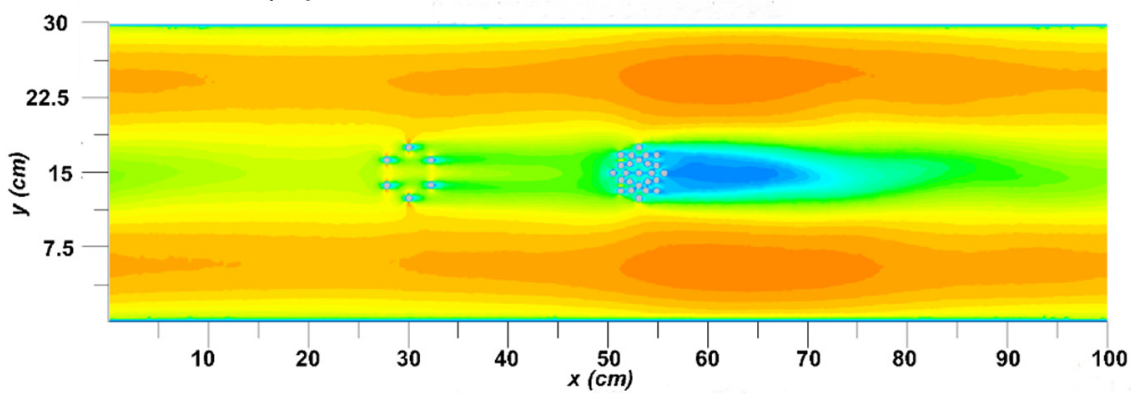

Fig. 10. Simulated streamwise velocity contours at a plane $z=6 \mathrm{~cm}$ for (a) Case-A, (b) Case-B, (c) Case-C and (d) Case-D.

and $w^{\prime}$ indicate the turbulence component of the velocity vectors along with the longitudinal, transverse and vertical directions. It is obvious from the plots of normal stresses that the maximum magnitude of these stresses exist near the topmost part of the vegetation $(z=h)$, which has been observed more significantly in Case-A and Case-C (Figure 11(a, c(i-iii))).

The reduction of Reynolds stresses near the bottom of the channel is due to considerable resistive shear stresses induced by the channel bed (Dey, 2014). The formation of Kelvin Helmholtz vortices results from the instability of flow at the top edge of patches. The generated vortices affect the turbulence. The instability in the flow occurs due to the mixing of lowvelocity flow with higher velocity flow (Raupach et al., 1996). The shear stresses $\left(-u^{\prime} w^{\prime}\right)$ at Position-3 and Position-4 located at distance $D / 2$ from the patches of flow blockage $(a D)$ of 2.4 and 3.54 are almost stable. 
(a)
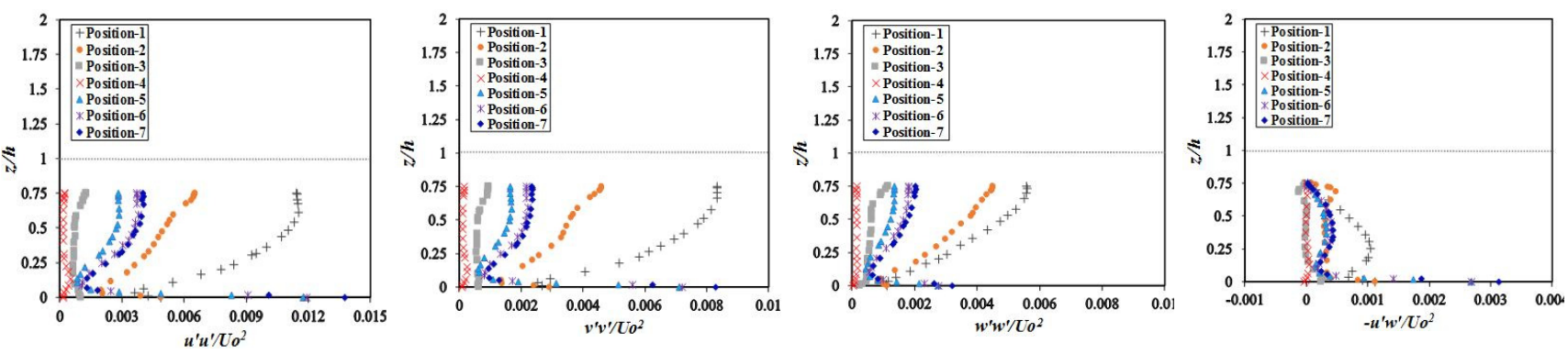

(b)
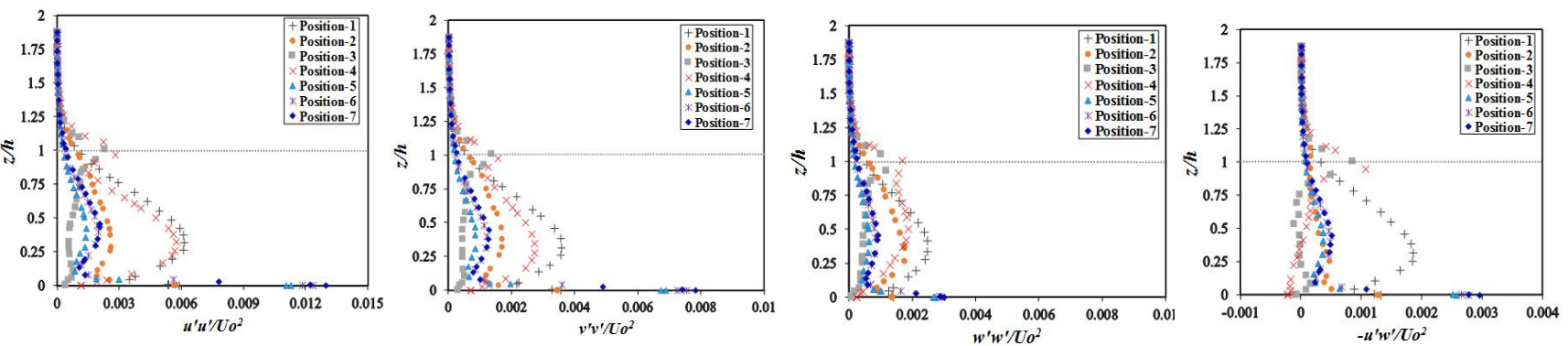

(c)
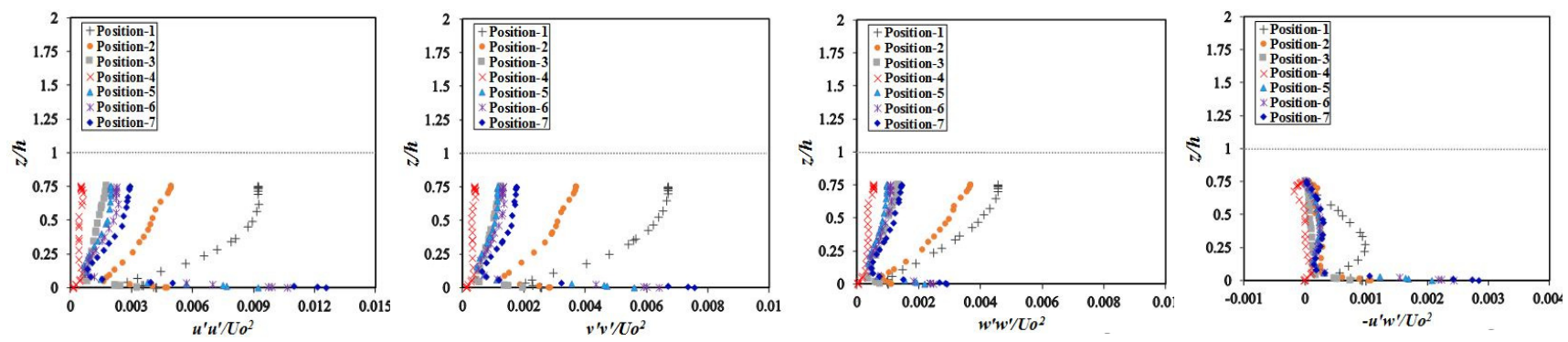

(d)

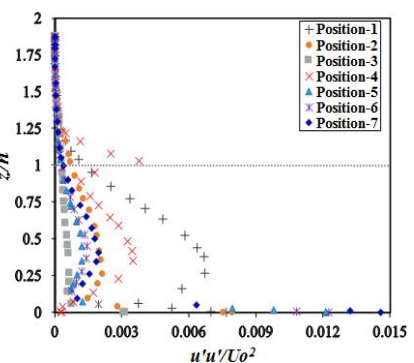

(i)

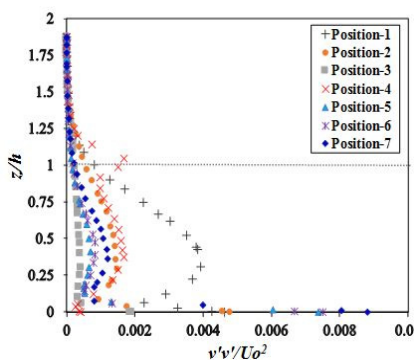

(ii)

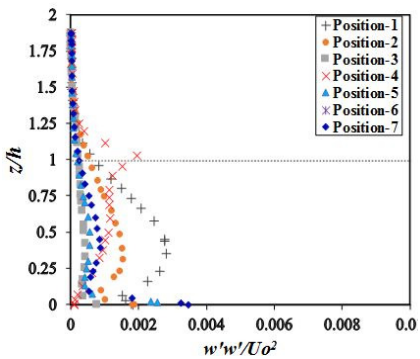

(iii)

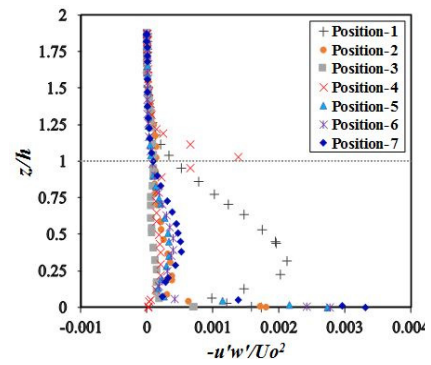

(iv)

Fig. 11. (i-iii) Reynolds normal stresses and (iv) Reynolds shear stresses for (a) Case-A, (b) Case-B, (c) Case-C, (d) Case-D for all specified locations.

However, fluctuations have been observed in submerged cases (Case-B and Case-D) above the patch height. The maximum magnitude of shear stress $\left(-u^{\prime} w^{\prime}\right)$ was found near $(z / h=0.30)$ at Position-1, located upstream of the first patch $(a D=0.8)$. The patterns of all the stress profiles were found similar to each other, however the variation exists in the magnitude at the boundary of the vegetated and non-vegetated region, i.e. $z / h=1$. The momentum transfer between the flow layer above the vegetation height and the inside vegetation layer yields these fluctuations (Raupach et al., 1996; Wang et al., 2009). The variation in magnitude at the top of vegetation for Position-4 is found to be larger than Position-3. However, no fluctuations were observed at Position-3 for Case-D (Figure $11 \mathrm{~d}(\mathrm{iv}))$. Thus the increase in vegetation density intends to increase the extents of fluctuation at the boundary layer of vegetated and non-vegetated regions.

\subsubsection{Turbulent intensity distributions}

Turbulent intensity (TI) is the ratio of the standard deviation of fluctuating velocity to the mean velocity of flow. The results for the numerically simulated turbulence intensity distribution have been plotted between the TI (\%) along the x-axis and normalized depth of flow $(z / h)$ along the y-axis. TI is measured in terms of percentage. The profiles at specified locations for four scenarios have been shown in Figure 12(a-d).

The turbulent intensities are directly related to velocities and higher where the magnitudes of velocities are large (Zhang, 2013). Therefore, it is notable from Figure 12(a-d) that TIs (\%) were higher for Position-1 than any other location for all the cases. The maximum and minimum percentage of TI for CaseA were $4.5 \%$ and $0.45 \%$, respectively. For Case-A, in the presence of the middle patch having a patch density of $182 \%$ higher 
than the $\mathrm{u} / \mathrm{s}$ first patch $(a D=0.8)$, the percentage of TI for $(z / h$ $=0.5$ ) was found to be $3.2 \%$ at Position-2. The density is increased up to $48 \%$ compared to the middle patch by introducing a dense patch downstream of the channel. This density increment has reduced velocity and influenced TI significantly. The percentage of TI at Position-3 was $1.3 \%$, while at Position- 4 , it was $0.6 \%$. Whereas for Case-C, there is no middle patch, hence providing a gap region between the two patches. Therefore, no direct influence of vegetation patch was observed at Position-2, which resulted in less percentage of TI that is $2.9 \%$. Higher values of TI $(\%)$ were observed at positions located near the patch due to direct obstruction to the flow which indicates that the vegetation free region is comparatively less turbulent that can be favourable for aquatic life. As the flow moved towards the downstream patch, regeneration of turbulence was observed at Position-3 and Position-4. In a comparison of Case-A and Case-C, distinct behavior of TI has been seen at Position-3. In Case-A, an almost straight curve has been observed, whereas in Case- $\mathrm{C}$, fluctuation in the curve was notable near the bed, similar to Position-2. The TI (\%) at Position-4 for Case-C was observed to be $64.3 \%$ higher than Case-A. The plots for all the Cases (Figure 12(a-d)) indicate that the TI was higher near the bed of the channel. Likewise, velocity, the profiles of TI in the free stream region (Position-5, 6 and 7) were found to be stable. It was observed that the TI was higher in the patches than in the gap between the patches. In Case-B, the peak in the TI (\%) was observed in submerged case over the patch height $(z / h=1)$ for Position-3 and Position-4 located downstream of the middle patch $(a D=2.4)$ and downstream patch $(a D=3.54)$, respectively. It was estimated that the peak value of TI (\%) at depth $(z / h=1)$ was $28 \%$ larger in Position-4 than Position-3. This high value then decreased to some extent at the water surface (Figure 12(b)).

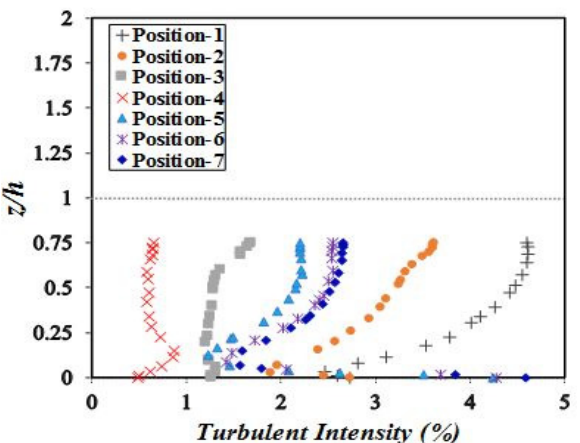

(a)

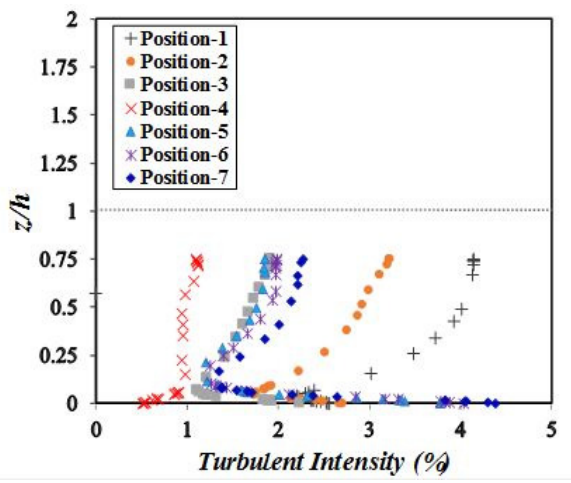

(c)
However, due to the non-existence of the middle patch, no fluctuation at depth $(z / h=1)$ was observed at Position-3 for Case-D (Figure 12(d)). The TI (\%) for Case-B at Position-3 was found to be $21 \%$ higher than Case-D (Figure 12(b)). The above discussion indicated that an increase in patch density produces flow fluctuations and causes turbulence. The turbulence is observed higher behind the vegetation patch due to momentum exchange at the interface. However, low turbulence is observed in the free stream region, where there is no direct obstruction to flow. This region implies adequacy for aquatic life.

\subsubsection{Turbulent kinetic energy}

It is the kinetic energy of flow per unit mass of eddies and swirls associated with turbulent flow. The plots of the depthwise simulated turbulent kinetic energy $(T K E)$ for the cases have been shown in Figure 13(a-d). The TKE was normalized with $U_{o}$ and plotted against normalized flow depth $(z / h)$.

It was observed that the magnitudes of $T K E$ were found to be higher at the upstream and downstream of the sparse patch $(a D=0.8)$ in Case-A and Case-C (Figure 13(a, c)). In previous studies, higher values of TKE were examined at the top edge of the patch $(z / h=1)$ (Anjum et al., 2018a; Hao et al., 2014). In submerged vegetation, the fluctuations in the normalized values of turbulent kinetic energy $\left(T K E / U_{o}^{2}\right)$ were observed at the topmost of the vegetation canopy. Maximum magnitudes of $T K E$ were witnessed within the vegetation patches than in the gaps aswas also observed by Anjum et al., (2018a). A low magnitude of turbulence was observed immediately ahead of the last vegetation patch $(a D=3.54)$ in Case-A and Case-C. However, higher magnitudes of TKE were found at Position-1 and Position- 4 for submerged cases (i.e. Case-B and Case-D) as represented in Figure 13(b, d).

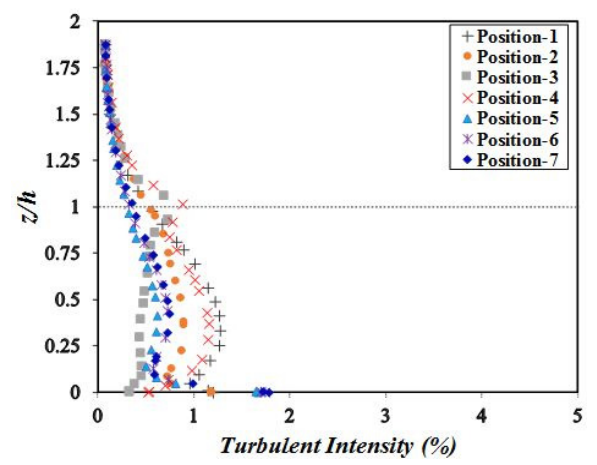

(b)

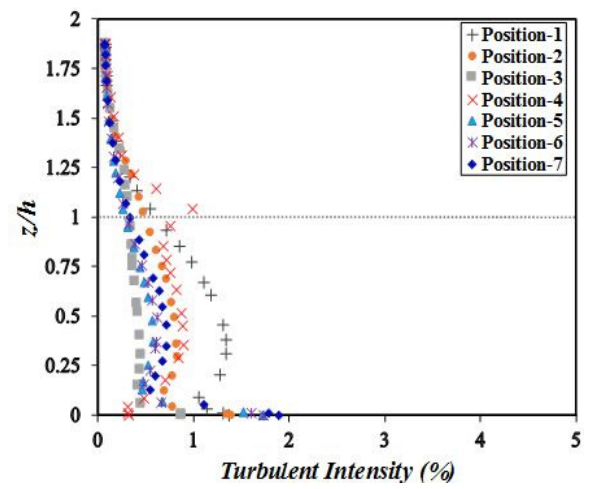

(d)

Fig. 12. Turbulent intensity (\%) at all specified locations for (a) Case-A, (b) Case-B, (c) Case-C and (d) Case-D. 


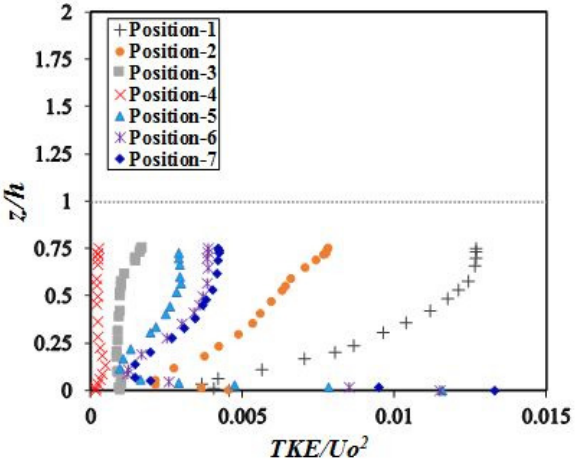

(a)

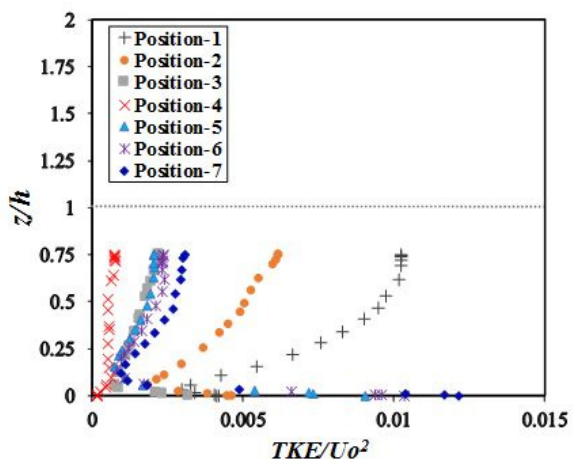

(c)

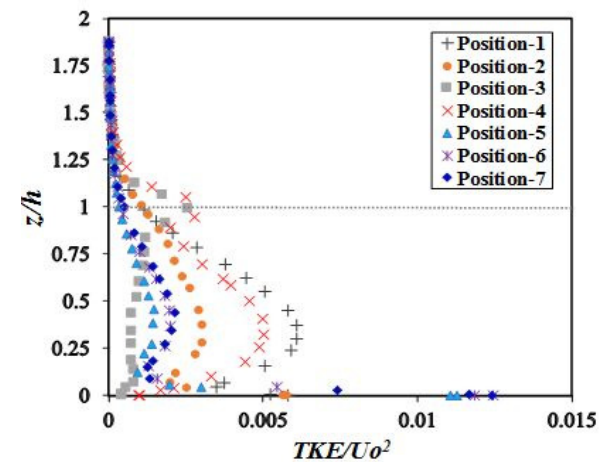

(b)

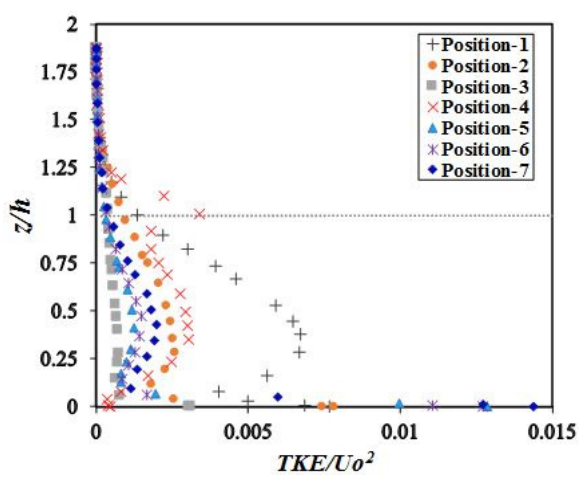

(d)

Fig. 13. Turbulent Kinetic Energy at specified locations for (a) Case-A, (b) Case-B, (c) Case-C and (d) Case-D.

\section{CONCLUSION AND RECOMMENDATIONS}

The flow vegetation interaction and the characteristics of flow around the circular vegetation patches have been explored in a rectangular open channel. The flow development around the varying densities of vegetation has been studied computationally at different locations using a Reynolds stress turbulence model. The results showed that streamwise circular vegetation patches with variable densities considerably influenced the flow structures. The following conclusions are drawn from the results:

1. The existence of vegetation patches within an open channel causes flow obstruction, which reduces the velocity of flow. The reduction in the magnitude of averaged velocities has been observed higher in submerged cases. There exists inflectional instability above the canopy region, which causes the mixing of two flow layers. The velocity difference at the interface of the vegetated and non-vegetated region yields momentum exchange. The flow attains higher velocities when there is no middle patch, which provides a greater clear distance between the two patches. Whereas higher velocity reductions have been observed in the presence of three in-lined circular patches, which gives a better response to the ecosystem, physical environment and sediment deposition.

2. In submerged cases, there exists an average height above the canopy zone i.e. $z / h \geq 1.7$ where flow properties become stable, and patch zone have no impact on the flow features. However, in the region $1 \leq z / h<1.7$, the inflectional instability of the flow properties has been observed due to the presence of varying density vegetated zone.

3. Flow velocity noticeably reduces due to vegetation drag when flow interacts with the patches. This reduction is observed significantly higher within the gap regions. The variation of flow properties at the interfacial zone has been observed for submerged cases.
4. The flow interaction with vegetation has increased the turbulence within the vegetation patches, which leads to an increase in the turbulence kinetic energy and turbulence intensities due to the drag force offered by the canopy zone. However, on the contrary, less turbulence is observed in the free stream zone. For a constant flow rate $(l / s)$, the turbulence energy is observed to be significantly lower for submerged vegetation arrangements than that of emergent vegetation arrangements, which provides a suitable environment to aquatic inhabitants.

5. It is concluded that with the increase in the vegetation density, turbulent intensity (TI) increases above the vegetation height. The TI (\%) for the submerged case with the three patches $\left(L_{a} / D=1\right)$ was higher than the submerged case without a middle patch. This specified that the plant morphology has a large impact on the momentum transfer due to the generation of interfacial turbulence.

This study can be made useful to understand the flows through discontinuous circular patches with variable density and in designing the aquatic ecosystem. This research can be implemented to the existing natural channels like river, streams, and floodplains for high flood seasons. The results obtained from the current study provide a better understanding of flood mitigation and its effects on the flow structures. It also provides guidance regarding the restoration of the ecological system and its management over the floodplains. This study will be helpful in flood mitigation, flow distributions, ecosystem and structural stability. For further investigation, varying discharge parameter, vegetation configurations and other factors that may influence the flood control are recommended. The effect of the flow features are needed to be examined thoroughly by changing the gaps between the patches. A comprehensive study is also required to demonstrate the impact of patches over sedimentation, conveyance and momentum exchange. 
Acknowledgement. The authors are thankful to the Higher Education Commission (HEC), Pakistan, for providing CFD facilities at the Civil Engineering Department, University of Engineering and Technology, Taxila, Pakistan. The authors are also grateful to Yasir Ali, Faisal Maqsood, Uzair Abdul Rab, and Syed Ali Shahbaz Shah for their contribution to experimental work, which was used to validate the numerical results.

\section{REFERENCES}

Ali, S., 2013. Investigation for required number of patches for numerical modelling in an open channel with checker. Life Sci. J., 10, 220-226.

Ali, Y., Maqsood, F., Abdul-Rab, U., Shah., 2018. Impact of vegetation pattern on flow behavior in an open channel. Research project. Department of Civil Engineering, University of Engineering and Technology, Taxila, Pakistan.

Anjum, N., Ghani, U., Pasha, G.A., Latif, A., Sultan, T., 2018 a. To investigate the flow structure of discontinuous vegetation patches of two vertically different layers in an open channel. Water, 10, 1, 75.

Anjum, N., Ghani, U., Pasha, G.A., Rashid, M.U, Latif, A., Yousaf, M.Z., 2018b. Reynolds stress modeling of flow characteristics in a vegetated rectangular open channel. Arab. J. Sci. Eng., 43, 10, 5551-5558.

Barrios-Piña, H., Hermilo, R., Clemente, R.C., Carlos, C.C., 2014. Multilayer numerical modeling of flows through vegetation using a mixing-length turbulence model. Water, 6, 7, 2084-2103.

Bertoldi, W., Annunziato S., Stefano, T., Marco, T., David, V., Simona, F., 2014. Modeling vegetation controls on fluvial morphological trajectories. Geophys. Res. Lett., 41, 20, 7167-7175.

Bouma, T.J.Ã., Van Duren, L.A., Temmerman, S., Claverie, T., Ysebaert, T., Herman, P.M.J., 2007. Spatial flow and sedimentation patterns within patches of epibenthic structures: combining field, flume and modelling experiments. Cont. Shelf Res., 27, 8, 1020-1045.

Cheng, N.S., 2011. Representative roughness height of submerged vegetation. Water Resour. Res., 47, 8, 1-18.

Chen, Z., Ortiz, A., Zong, L., Nepf, H., 2012. The wake structure behind a porous obstruction and its implications for deposition near a finite patch of emergent vegetation. Water Resour. Res., 48, 9, 9517.

Dan, N., Iehisa, N., Hiroji, N., 1996. Hydrodynamic behaviour of partly vegetated open channels. J. Hydraul. Eng., 122, 11, 625-633.

Devi, T.B., Kumar, B., 2016. Flow characteristics in an alluvial channel covered partially with submerged vegetation. Ecol. Eng., 94, 478-492.

Dey, S., 2014. Turbulence in open-channel flows. Fluvial hydrodynamics, GeoPlanet: Earth and Planetary Sciences, 95187.

Dieter, W.S.A., Meire, J., Kondziolka, M., Nepf, H.M., 2014. Interaction between neighboring vegetation patches: impact on flow and deposition., Water Resour. Res., 50, 5, 38093825.

Ghisalberti, M., Nepf, H.M., 2004. The limited growth of vegetated shear layers. Water Resour. Res., 40, 1-12.

Ghani, U., Anjum, N., Pasha, G.A., Ahmad, M., 2019a. Investigating the turbulent flow characteristics in an open channel with staggered vegetation patches. River Res. Appl., 35, 7, 966-978.

Ghani, U., Anjum, N., Pasha, G.A. Ahmad, M., 2019b. Numer- ical investigation of the flow characteristics through discontinuous and layered vegetation patches of finite width in an open channel. Environ. Fluid Mech., 19, 1469-1495.

Goharzadeh, A., Molki, A., 2014. Measurement of fluid velocity development behind a circular cylinder using particle image velocimetry (PIV). European Journal of Physics, 36, 1, 015001.

Hao, W., Tang, H., Yuan, S., Shengqi, L.V., Zhao, X., 2014. An Experimental study of the incipient bed shear stress partition. Science China Technological Sciences, 57, 11651174.

Huai, W., Wang, W., Hu, Y., Zeng, Y., Yang, Z., 2014. Analytical model of the mean velocity distribution in an open channel with double-layered rigid vegetation. Adv. Water Resour., 69, 106-113.

Jalonen, J., Juha, J., Pekka, J., Virtanen, M.V., Kurkela, M., Hyyppä, H., 2015. Determining characteristic vegetation areas by terrestrial laser scanning for floodplain flow modeling. Water, 7, 2, 420-437.

Jordanova, A.A., James, C.S., 2003. Experimental study of bed load transport through emergent vegetation. J. Hydraul. Eng., 129, 6, 474-478.

Kamel, B., Ilhem, K., Ali, F., Abdelbaki, D., 2014. 3D simulation of velocity profile of turbulent flow in open channel with complex geometry. Phys. Procedia., 55, 119-128.

Kouwen, N., Unny, E., 1973. Flexible roughness in an open channel. J. Hydraulics Division., 99, 5, 713-728.

Leonard, L.A., Mark, E.L., 1995. Flow hydrodynamics in tidal marsh canopies. Limnol. Oceanogr., 40, 8, 1474-1484.

Li, W., Wang, D., Jiao, J., Yang, K., 2019. Effects of vegetation patch density on flow velocity characteristics in an open channel. J. Hydrodyn., 31, 1052-1059.

López, F., García, M., 1998. Open-channel flow through simulated vegetation: turbulence modeling and sediment transport. Water Resour. Res., 34, 9, 2341-2352.

Maltese, A., Eleanor, E.C., Andrew, A., Folkard, M., Giuseppe, G., Ciraolo, G., Giovambattista, G.L., 2007. Laboratory measurements of flow and turbulence in discontinuous distributions of ligulate seagrass. J. Hydraul. Eng., 133, 7, 750-760.

Neary, V.S., Constantinescu, S.G., Bennett, S.G., Diplas, P., 2012. Effects of vegetation on turbulence, sediment transport, and stream morphology. J. Hydraul. Eng., 138, $765-776$.

Nepf, H.M., 1999. Drag, turbulence, and diffusion in flow through emergent vegetation. Water Resour. Res., 35, 2, 479-489.

Nepf, H.M., Vivoni, E.R., 2000. Flow structure in depthlimited, vegetated flow. J. Geophys. Res. Oceans, 105, C12, 28547-28557.

Neumeier, U., 2007. Velocity and turbulence variations at the edge of saltmarshes. Cont. Shelf Res., 27, 8, 1046-1059.

Nishino, T., Graham, T.R., Xin, Z., 2007. Vortex shedding from a circular cylinder near a moving ground. Phys. Fluids., 19, 1-13.

Pasha, G.A., Tanaka, N., 2016. Effectiveness of finite length inland forest in trapping tsunami-borne wood debris. J. Earthq. Tsunami, 10, 2, 1-26.

Pasha, G.A., Tanaka, N., Yagisawa, J., Achmad, F.N., 2018. Tsunami mitigation by combination of coastal vegetation and a backward-facing step. Coast. Eng. J., 60, 1, 1-22.

Prasad, Y., Tang, Q., 2015. Soil bioengineering application for flood hazard minimization in the foothills of siwaliks, Nepal. Ecol. Eng., 74, 458-462.

Rajaratnam, N., 2006. Review of turbulent jets and plumes - A Lagrangian approach by Joseph H.W. Lee and Vincent H. Chu. 
Kluwer Academic Publishers, Dordrecht, The Netherlands; 2003; 408 pp. Price: \$135. J. Hydraul. Eng., 132, 8, 873. https://doi.org/10.1061/(ASCE)0733-9429(2006)132:8(873)

Raupach, M.R., Finnigan, J., Brunet, Y., 1996. Coherent eddies and turbulence in vegetation canopies: the mixing-layer analogy. Boundary-Layer Meteorology, 78, 351-382.

Righetti, M., Armanini, A., 2002. Flow resistance in open channel flows with sparsely distributed bushes. J. Hydrol., 269, 1-2, 55-64.

Rominger, J.T., Nepf, H.M., 2011. Flow adjustment and interior flow associated with a rectangular porous obstruction. J. Fluid Mech., 680, 636-659.

Shucksmith, J.D., Boxall, J.B., Guymer, I., 2010. Effects of emergent and submerged natural vegetation on longitudinal mixing in open channel flow. Water Resour. Res., 46, 4, 1-14.

Suk, H., Nabi, M., Kimura, I., Shimizu. Y., 2015. Advances in water resources computational modeling of flow and morphodynamics through rigid-emergent vegetation. Adv. Water Resour., 84, 64-86.

Takemura, T., Tanaka, N., 2007. Flow structures and drag characteristics of a colony-type emergent roughness model mounted on a flat plate in uniform flow. J. Fluid Dyn. Res., 39, 9-10.

Tanaka, T., Uchida, E., Yokota, T., Hagihara, A., Takeda, Y., 1993. Comparison between water absorption rate and sapflow rate measured using the improved stem heat-balance method. J. Jpn. For. Soc., 76, 554-557.

Tatsuno, M., Amamoto, H., Ishi, K., 1998. Effects of interference among three equidistantly arranged cylinders in a uniform flow. J. Fluid Dyn. Res., 22, 5, 297-315.

Wang, C., Yu, J.Y., Wang, P.F., Guo, P.C., 2009. Flow structure of partly vegetated open-channel flows with eelgrass. J. Hydrodyn., 21, 3, 301-307.

Wang, Z., Lu, J., Yuan, Y., Huang, Y., Feng, J., Li, R., 2019. Experimental study on the effects of vegetation on the dissipation of supersaturated total dissolved gas in flowing water. Int. J. Environ. Res. Public Health, 16, 13, 2256.
Xiaohui, S., Li, C.W., 2002. Large eddy simulation of free surface turbulent flow in partly vegetated open channels. Int. J. Numer. Methods Fluids, 39, 10, 919-937.

Xiaonan, T., Knight, D.W., 2009. Lateral distributions of streamwise velocity in compound channels with partially vegetated floodplains. Sci. China Technol. Sci., 52, 3357-3362.

Yu, L.H., Zhan, J.M., Li, Y.S., 2013. Numerical investigation of drag force on flow through circular array of cylinders. J. Hydrodyn., 25, 3, 330-338.

Zeng, C., Li, C.W., 2014. Measurements and modeling of openchannel flows with finite semi-rigid vegetation patches. Environ. Fluid Mech., 14, 113-134.

Zhang, H., Yang, J.M., Xiao, L.F., Lü, H.N., 2015. Large-eddy simulation of the flow past both finite and infinite circular cylinders at $\operatorname{Re}=3900$. J. Hydrodyn., 27, 2, 195-203.

Zhang, L.Z., 2013. Heat and mass transfer across a hollow fiber membrane bundle. In: Conjugate Heat and Mass Transfer in Heat Mass Exchanger Ducts. Academic Press, pp. 181-232.

Zhang, M., Li, C.W., Shen, Y., 2013. Depth-averaged modeling of free surface flows in open channels with emerged and submerged vegetation. Appl. Math. Model., 37, 540-553.

Zhao, F., Huai, W., 2016. Hydrodynamics of discontinuous rigid submerged vegetation patches in open-channel flow. J. Hydro-Environ. Res., 12, 148-160.

Zhan, J., Hu, W., Cai, W., Gong, Y., 2017. Numerical simulation of flow through circular array of cylinders using porous media approach with non-constant local inertial resistance coefficient. J. Hydrodyn., 29, 1, 168-171.

Zong, L., Nepf, H., 2011. Vortex development behind a finite porous obstruction in a channel. J. Fluid Mech., 691, 368-391.

Zhenqun, W.U., Guobiao, O.U., Yifei, R.E.N., Hui, J.I.N., 2020. Numerical investigation on the drag characteristics of supercritical water flow past a sphere. Sci. China Technol. Sci., 63, 1509-1519.

Received 22 January 2021 Accepted 1 July 2021 